\title{
The Design of Disciplinarily-Integrated Games as Multirepresentational Systems
}

\author{
Satyugjit S. Virk, Vanderbilt University, United State, Nashville, TN, USA \\ Douglas B Clark, Werklund School of Education, University of Calgary, Calgary, Canada \\ Pratim Sengupta, Werklund School of Education, University of Calgary, Calgary, Canada
}

\begin{abstract}
Disciplinarily-integrated games represent a generalizable genre and template for designing games to support science learning with a focus on bridging across formal and phenomenological representations of core science relationships (Clark, Sengupta, Brady, Martinez-Garza, and Killingsworth, 2015; Clark, Sengupta, \& Virk, 2016; Sengupta \& Clark, 2016). By definition, disciplinarily-integrated games (DIGs) are therefore multirepresentational systems with the affordances and challenges associated with that medium. The current paper analyzes the DIG structure through the focal parameters framed by the DeFT framework (Ainsworth, 2006) to synthesize effective design considerations for DIGs in terms of the specific design and intended functions of the representations themselves as well as the overarching environment and activity structures. The authors leverage the literatures on embodied cognition, adaptive scaffolding, representations in science education, and learning from dynamic visualizations to address the challenges, tradeoffs, and questions highlighted by the framework. They apply these research-derived design considerations to an existing DIG (SURGE Symbolic) and to hypothetical examples of other DIGs in other domains to explore generalizability of the design considerations and the genre.
\end{abstract}

\section{KEYWORDS}

Ainsworth, Cognitive Flexibility, DeFT, Design Thinking, DIGs, Multiple Representations, Representational Bridges, Science Educational Technologies

\section{INTRODUCTION}

Clark et al. (2015) propose an approach for leveraging digital games as a medium to support the development of scientific modeling in K-12 classrooms based on the Science as Practice perspective (Pickering, 1995; Lehrer \& Schauble, 2006). Clark et al. (2015) refer to this approach as disciplinary integration. Disciplinarily-integrated games (DIGs) represent a generalizable genre and template for designing games to support science learning in order to bridge across formal and phenomenological representations of core science relationships. Therefore, by definition, DIGs are multirepresentational systems with the affordances and challenges associated with that medium.

Ainsworth (2014) highlights the importance of articulating broader theoretical frameworks to investigate how multiple representations improve learning and under what conditions. She also 
highlights the importance of explicitness in articulating the design and function of representations in multirepresentational systems so that research across the field can move beyond simplistic comparisons to instead drill deeper into how specific design decisions affect learning processes in light of specific intended functions of the multirepresentational system.

More specifically, this paper seeks to analyze the DIG genre and template through the focal parameters framed by the DeFT framework (Ainsworth, 2006) to synthesize effective design considerations for DIGs in terms of the specific design and intended functions of the representations themselves as well as the overarching environment and activity structures. We leverage the literatures on embodied cognition, adaptive scaffolding, representations in science education, and learning from dynamic visualizations to address the challenges, tradeoffs, and questions that the framework highlights. We apply these research-derived design considerations to an existing DIG (SURGE Symbolic) and to hypothetical examples of DIGs in other domains to investigate the generalizability of the design considerations and the genre.

\section{DISCIPLINARY INTEGRATION}

As we have asserted in our earlier papers (Clark et al., 2015; Sengupta \& Clark, 2016), modeling is generally recognized as the core disciplinary practice in science (Lehrer \& Schauble, 2002; Nercessian, 2008; Pickering, 1995). Science and math education research shows that engaging learners in modeling and progressively refining representations can contribute to a deeper understanding of mathematical and scientific knowledge and practices (Gravemeijer, Cobb, Bowers, \& Whitenack, 2000; Hall \& Stevens, 1995; Lehrer \& Schauble, 2009). Clark et al. (2015) and Sengupta and Clark (2016) suggest that DIGs are a generalizable genre and template for supporting players in interpreting, manipulating, and translating across phenomenological and formal representations in support of a Science as Practice perspective.

Disciplinary integration can be conceptualized in terms of Allan Collins's analyses of "model types" and "modeling strategies" (Collins, 2017), which Collins and colleagues have termed "epistemic forms" and "epistemic games" in earlier work (Collins, 2011; Collins \& Ferguson, 1993; Morrison $\&$ Collins, 1995). They argue that scientists' professional work can be understood in terms of model types (epistemic forms) that are the target structures guiding scientific inquiry and modeling strategies (epistemic games) that are the sets of rules and strategies for creating, manipulating, and refining those model types. While Collins and colleagues did not write with the intention of influencing the design of actual digital games (they used the term "game" as a metaphor), DIGs can leverage the ideas of Collins and colleagues by structuring digital game play around modeling strategies (epistemic games) of designing and manipulating formal disciplinary model types (epistemic forms). More specifically, the puzzles and game-play mechanics of disciplinarily-integrated games distill model types and the modeling strategies for navigating and working with those models.

As Clark et al. (2015) discuss, this specific emphasis on modeling as game play around disciplinary model types stands in contrast to engaging in "inquiry" more broadly, as is common in 3D virtual worlds (e.g., Quest Atlantis, River City, or Crystal Island). Essentially, whereas 3D virtual inquiry worlds typically cast players as scientists investigating a phenomenon at the level of overarching inquiry, DIGs do not attempt the depth of immersion, identity-building, and role-playing of virtual inquiry worlds (and do not dispute their importance or value). Instead, DIGs are designed to engage players deeply in the specific modeling and representational practices of developing, interpreting, manipulating and translating across specific model types. This focus allows DIGs to iteratively deepen the puzzle at the heart of the game and, more broadly, all elements of the game to emphasize that puzzle.

Throughout this paper, we will discuss SURGE Symbolic as an example of a DIG (Figure 1, http://www.surgeuniverse.com), but we will also explore generalizability to hypothetical DIGs for other disciplinary topics. We describe the design evolution leading to SURGE Symbolic in Clark, Virk, Sengupta et al. (2016). As described in Clark, Virk, Sengupta, et al. (2016), in addition to the 
Figure 1. SURGE Symbolic

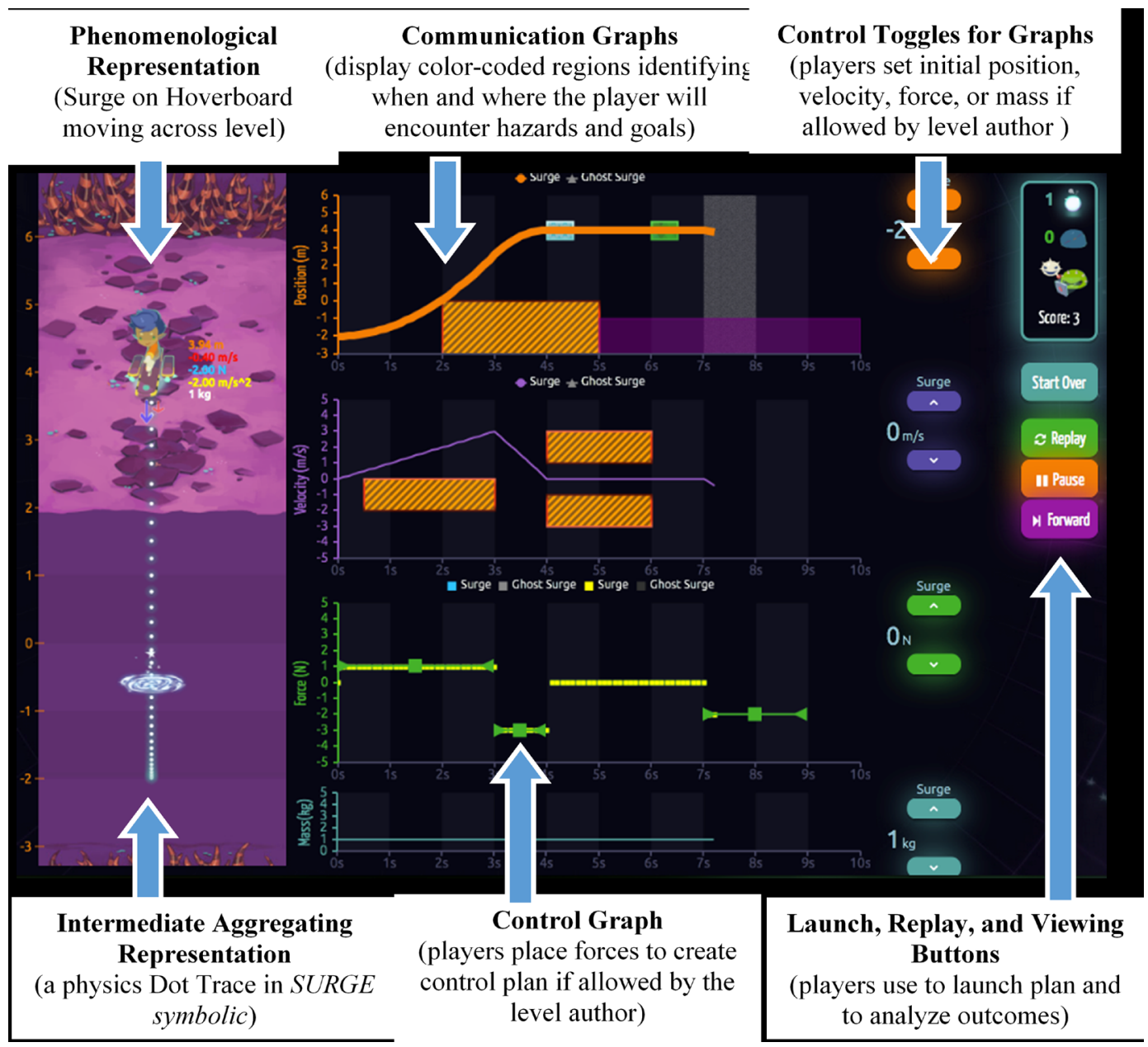

theoretical foundations discussed above, SURGE Symbolic also contributes to research on teaching with simulations and motion sensors (e.g., Brasell, 1987; Mokros \& Tinker, 1987), in general, and research on SimCalc (Kaput, 1992; Hegedus \& Roschelle, 2013), in particular. For example, students are often challenged to replicate or create graphs of position or velocity using various control schemes (e.g., a motion sensor). Similarly, learners have been tasked with interpreting a dot trace representation overlaid on a phenomenological view in terms of a graph. SimCalc supported learners' integration and differentiation between and across Cartesian graphs of position, velocity, and acceleration by dynamically linking across representations (Kaput, 1992; Hegedus \& Roschelle, 2013).

DIGs extend this seminal research in the context of Cartesian graphs of change over time by pushing more deeply on approaches for leveraging formal representations as the means of communicating challenges to players as well as pushing more deeply on formal representations as the players' tools for control over the game. Furthermore, DIGs reach and generalize well beyond time-series analyses and Cartesian graphs of change over time.

DIGs, by definition, use formal representations to communicate challenges and opportunities to the player (Communication Representations), and DIGs use formal representations as the medium through which the player implements strategies and exerts control over the game (Control Representations). 
Some DIGs may use the same representation for both control and communication, while other DIGs may use one or more formal representations for communication and one or more other representations for control. All DIGs include a phenomenological representation that would most likely be the primary focus in traditional digital games. DIG game mechanics and goals concentrate on interpreting, creating, modifying, and translating across these formal and phenomenological representations. Finally, DIGs embed the multirepresentational system within an central game narrative and dialog to scaffold translation across representations (Figure 2).

The template for SURGE Symbolic, for example, features the phenomenological representation (which we refer to as "the world" or "world view") on the left side of Figure 1. The phenomenological representation (or "world view") is the focus of most recreational games. It is where the player's avatar in the game moves around and engages in the game. It is the game "world." In SURGE Symbolic, the phenomenological representation portrays the heroine, Surge, on her hoverboard moving forward and backward along a game map. The formal Cartesian graphs on the right side act as the communication and control representations. The position graph in Figure 1, for example, can communicate information about the specific regions of the game-world that will be affected by dangerous electrical storms at given times, as well as the locations where rewards or allies will rendezvous with Surge. For example, if the player marks a path of four meters upwards over four seconds on this graph, Surge will consequently move four meters upward in four seconds in the animated world view. As a result of this design approach, the Cartesian space emerges as a set of scientific instruments for the player, and communicates data about the game world that are not available through other means. Figure 1 shows an example where the challenges and opportunities are communicated through the position graph, but the velocity and force/acceleration graphs can also serve this role. Simultaneously, the Cartesian graphs also act as an instrument panel or mission planner, offering fine-grained control over the movement of the Surge spacecraft. In Figure 1, for example, the player can control SURGE's movement by placing forces of various magnitudes and durations and different times in the force graph. Alternatively, the player can exert control through the other graphs depending on the specific game level's settings.

The proposed specific template and broader DIG genre must be generalizable to be valuable. To explore this claim of generalizability, the following paragraphs suggest other hypothetical examples of

Figure 2. Dialog system supports translation across representations with explanation prompts

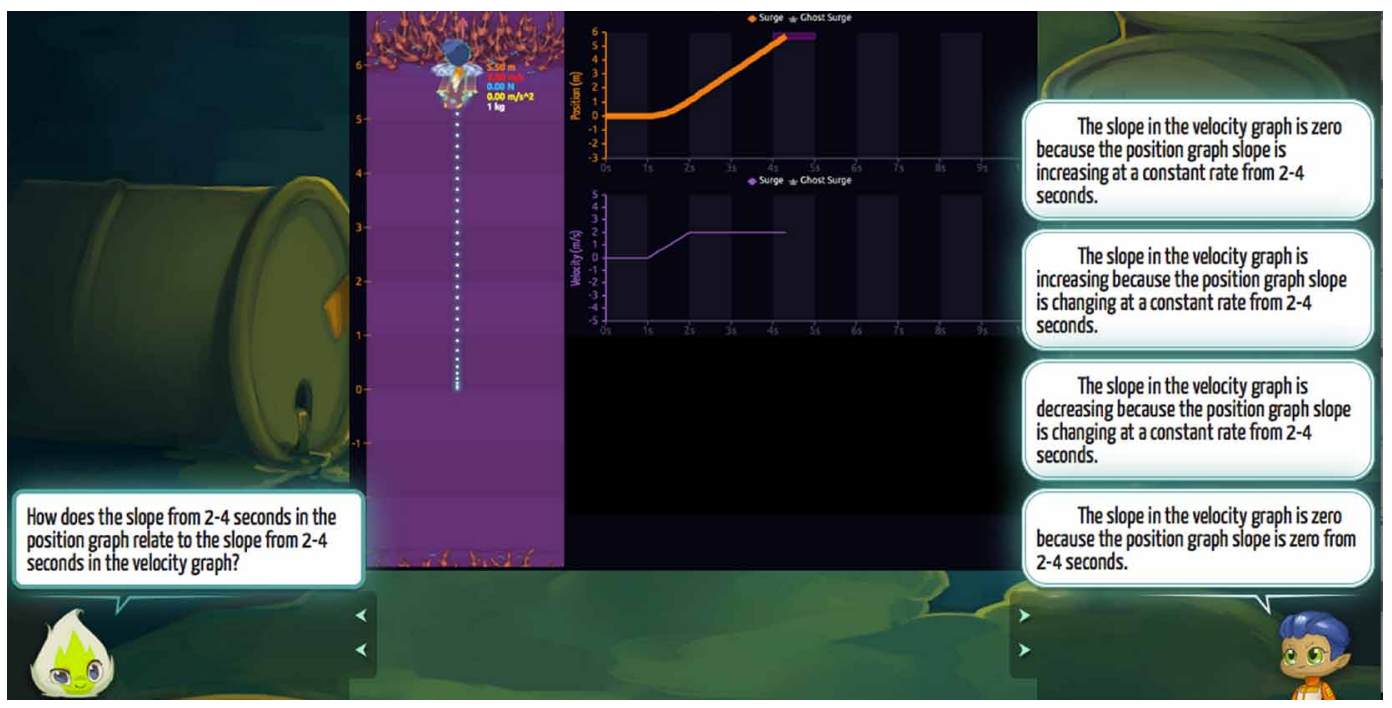


DIGs in physics, biology, chemistry, and the social sciences. These paragraphs build upon expand our earlier book chapter that explored generalizability of the DIG genre (Clark, Sengupta, \& Virk, 2016).

The nearest transfer of the DIG template is to other topics focusing on time-series analyses where Cartesian graphs of change over time remain the main formal representations. In these cases, the template outlined above transfers relatively directly. This is because the DIG template remains essentially identical to time series analyses as the modeling strategy and Cartesian representations of change over time as the model type.

One example would be exploring predator-prey relationships in population ecology. The timeseries analysis of the populations could concentrate on the formal representation of population versus time, which depict the classic Lotka-Volterra equation relationships (Figure 3). Perhaps the phenomenological representation depicts predator and prey within a given area moving and reproducing, eating, and being eaten. The phenomenological and formal representations could be bridged by an intermediate representation that aggregates, or stacks, the animals in the phenomenological representation to clearly communicate population levels. In terms of narrative, the game might be called Alien Zookeeper, and position the player as an alien zookeeper who needs to manage populations within the zoo. Perhaps the zookeeper can adjust temperature and irrigation in the zoo. As per the DIG template, the challenges and opportunities in a game level are presented within the formal representation itself, perhaps as target levels for various populations at various times to avoid or attain as part of the narrative. Also in line with the DIG template, the player outlines her strategy in another formal representation, perhaps temperature and irrigation levels over time, which impact plant growth and activity levels of predator and prey.

Figure 3. Classic Lotka-Volterra predator-prey population graph

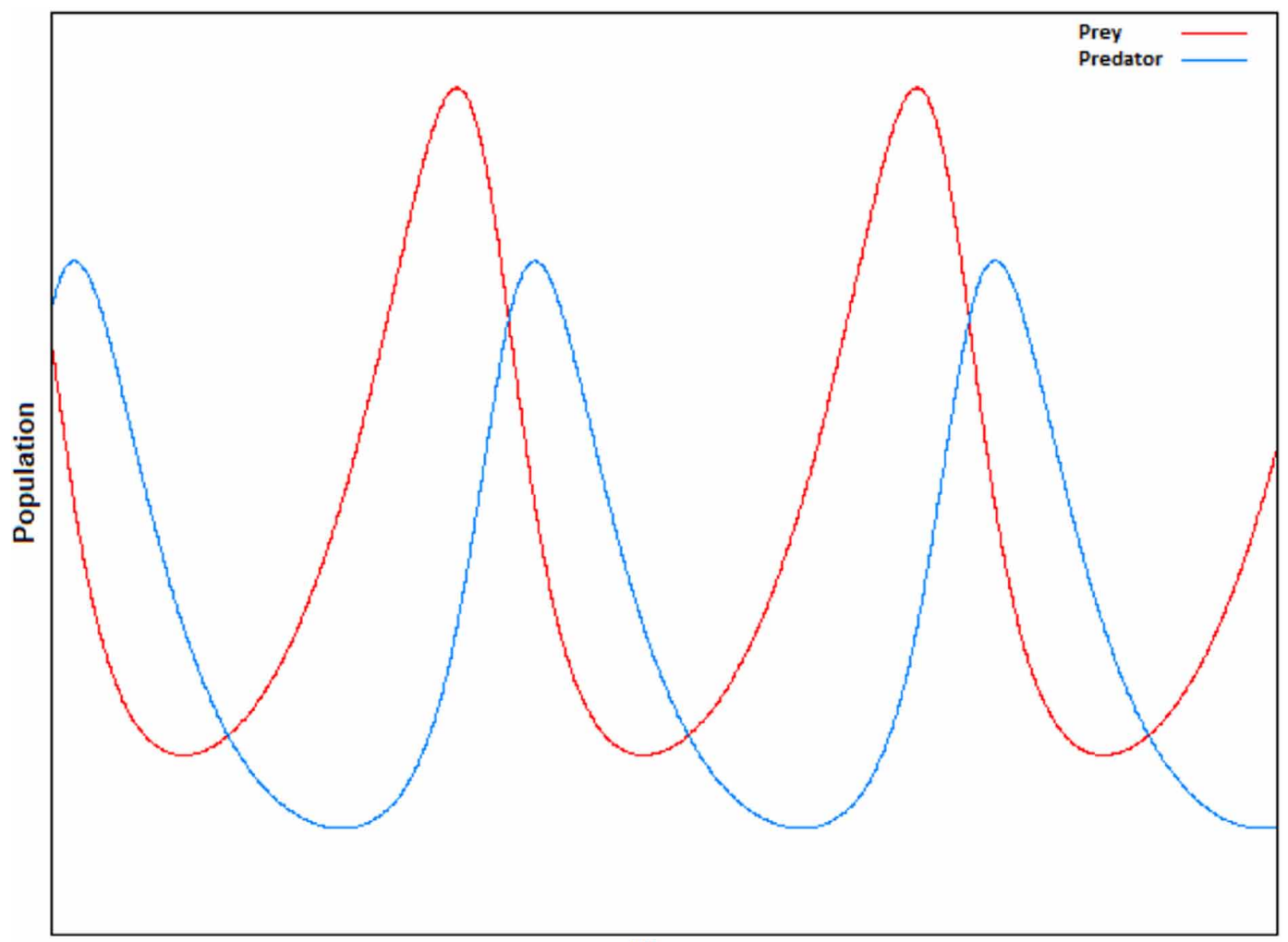


In terms of other possible topics, the phenomenological view in a DIG for teaching chemical reaction kinetics might involve a cylinder with various reactant molecules combining to create products. In terms of narrative, the player might need to create a certain number of products by a certain time because the cylinder is being used to create a series of pills to help cure a disease. In a DIG about the action potential, players may need to generate the specific membrane potential-over-time graph in question because they are trying to remotely control an alien organism they have engineered and set loose on a foreign planet. All of these proposed DIGs focus on time-series analyses with Cartesian formal representations, so all would use a very similar design template. Essentially, the game would communicate challenges and opportunities to the player through the formal representations, and the player would manipulate and create her strategy and actions through the formal representations.

How about generalizing beyond Cartesian time-series analyses? We propose that the next most proximal category of DIGs concentrates on the constraint systems that include Cartesian representations with axes other than time. Collins and colleagues outline constraint systems as process/behavioral analyses where: (a) the model type is the equation (or equations) describing the steady state of the system and (b) the most common modeling strategy is the controlling variables game where one variable is manipulated while all others are held constant to determine its behavior on the system. Constraint-system analyses thereby lend themselves to presenting relationships using Cartesian graphs as the formal representation with one variable along each axis and the other variables as controls for manipulating the Cartesian graph.

In the domain of chemistry, the ideal gas law is one potential example of a constraint-system analysis DIG. The ideal gas law is governed by the equation PV $=$ nRT, where notably "P" indicates pressure, "V" indicates volume, and " $T$ " indicates temperature. Here, the phenomenological view would be a simulation game environment where molecules travel around in a container. The player can make the container larger or smaller (volume) by adding or removing blocks, and the player can increase or decrease the temperature by changing the size of a flame. In this game, perhaps called Kinetic Explorer, the player would need to manipulate pressure, volume, and temperature to manage specialized cells that power a hovercraft she uses to explore an alien world. Here, Cartesian graphs of pressure-versus-volume, volume-versus-temperature, and temperature-versus-pressure become the representations of control and communication.

Another example, in the domain of physics, is the constraint system of Coulomb's force of repulsion and attraction. The narrative might cast the player as a space explorer on a spaceship. The player tries to achieve the right amount of repulsion or attraction between charge spheres in an alien device to navigate through play space (parallel to game play in SuperCharged, Squire et al, 2004, but played out in the formal representations rather than in a simulated world).

The previous paragraphs assert that the DIG template and genre proposed in this paper are generalizable to topics focusing on time-series analyses and constraint-system analyses where the formal representations of communication and control are Cartesian graphs. But what about topics beyond these model types? System-dynamics models also seem promising for DIGs because they involve specifying relationships and action sequences that influence outcomes given a scenario or set of parameters. In a system-dynamics model, variables are tied together by positive or negative links. Variables can be increased or decreased, which subsequently change other variables in the system though the links. Various lag, homeostatic, or feedback functions can be integrated with the models. Climate, economic, ecological, and other models in many disciplines can be designed as system-dynamics models. Figure 4 presents basic system-dynamics models for economics and for population ecology.

Could interesting game-play be built on interpreting and manipulating a system-dynamics model? Actually, such games have already been created as a recreational "indie" franchise that has been highly successful commercially. Democracy I, II, and III are essentially system-dynamics models (http:// www.positech.co.uk), in which the changes you make to individual variables influence all of the connected variables (either positively or negatively depending on the valence and magnitude of the 


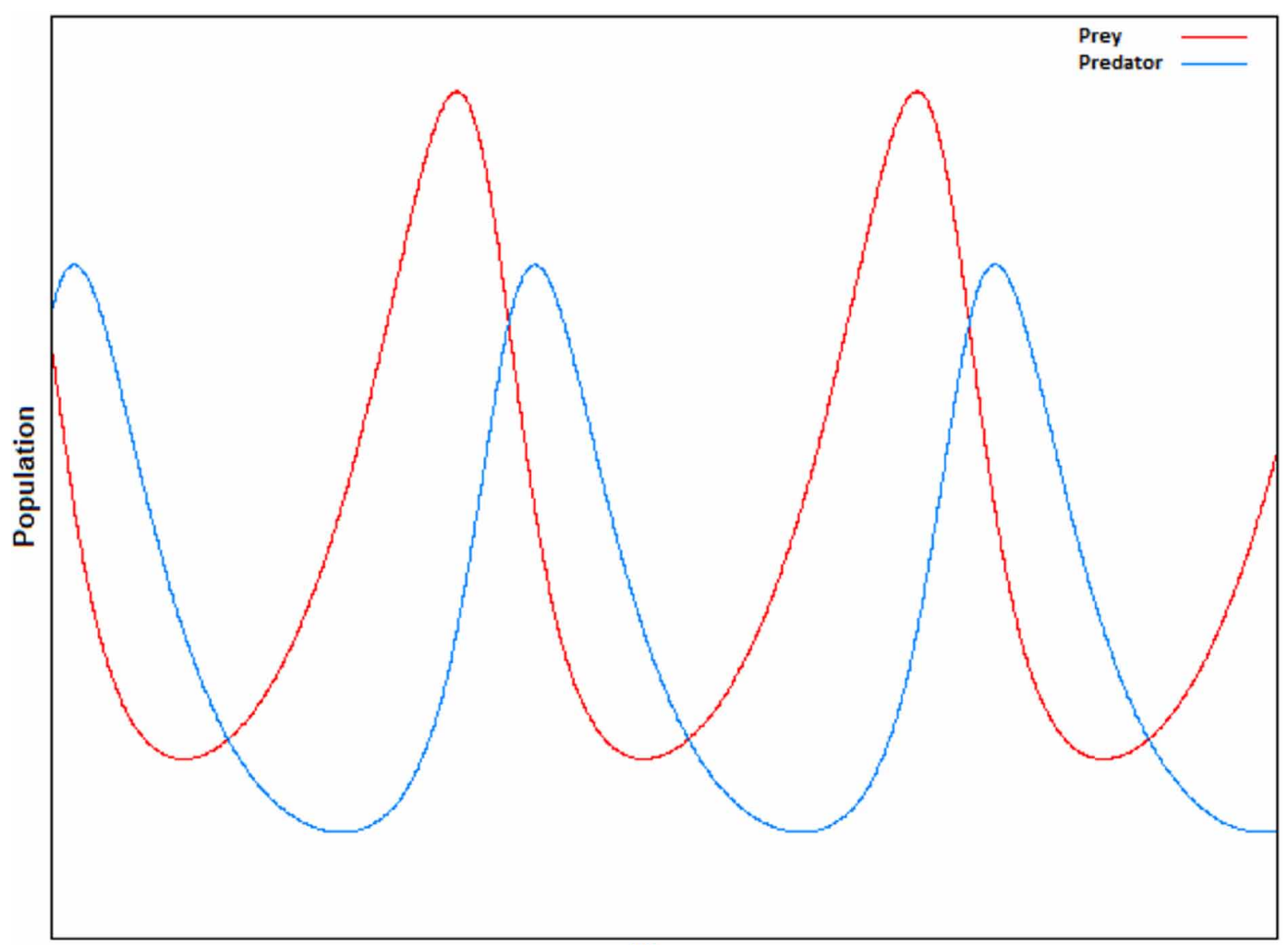

Time

link). Democracy is an excellent example because all of the game-play is centered and focused in the formal representations. Thus system-dynamics models, together with other formal representations, are clearly viable for DIGs. Rather than using Cartesian change-over-time graphs as the control representations, for instance, players might manipulate the population system-dynamics model in Figure 4 to plan and author strategies, while a Cartesian graph of populations over time might be employed as the communication representation that presents the challenges and opportunities for the level (perhaps Zookeeper System Dynamics).

The key commonality in all of these hypothetical DIGs is that framing disciplinary integration in terms of model types and model strategies enables us to design games in multiple disciplines. We propose that these examples comprise only a subset of DIGs and model types possible, potentially making DIGs highly generalizable across the curriculum.

\section{APPLYING THE DEFT FRAMEWORK TO MULTIPLE REPRESENTATIONS IN DIGS}

Ainsworth's (2006) DeFT framework for learning with multiple representations highlights the importance of analyzing the unique design parameters of multirepresentational systems, the functions they serve in enhancing learning, and the cognitive tasks in which learners must engage. Under DeFT, multiple external representations serve three functions: (1) complementary functions, (2) constraining functions, and (3) constructing functions. Complementary representations differ in the information they contain or the processes they support. Utilizing complementary representations 
can potentially provide learners with the advantages of each representation. Representations can also serve a constraining role, where a more familiar or accessible representation constrains understanding of a more complex representation. Finally, representations can serve a constructing function when learners integrate information across representations to develop deeper understanding than would be possible with a single representation.

The DeFT framework proposes five key parameters that require articulation and consideration when analyzing the design of a multirepresentational system: (1) number of representations, (2) information, (3) form, (4) sequence, and (5) translational activities. In this paper, we explore DIGs through these parameters in light of the research on single and multiple representations, embodied cognition, segmenting, signaling, comparing and contrasting, adaptive scaffolding, and learning from dynamic visualizations. Within each section, we articulate design considerations that the research suggests are critical to the design of DIGs in terms of the functions and tasks for which they are intended. We then explore examples of how the design considerations might be implemented in SURGE Symbolic and other hypothetical DIGs.

\section{PARAMETER 1: NUMBER OF REPRESENTATIONS}

The first parameter discussed in DeFT involves determining the optimal number of representations. Ainsworth (2006) advocates using the smallest number of representations that will effectively support the intended instructional function of the system. She further explains that the decision for how many representations to use is guided by the informational and computational properties of the system. Before determining the fewest number of representations for a DIG, let's start with understanding the importance of intermediate representations in these systems, leading to our first design consideration:

\section{Intermediate Representations - Use Constraining Intermediate Abstractions and Representations to Bridge between Phenomenological and Formal Representations}

Research on intermediate abstractions is critical to thinking about the design of DIGs. Several researchers have argued for the use of intermediate abstractions in the form of dynamic visualizations for learning physics. For example, White (1993) argued that, instead of teaching learners physics by directly teaching them physics principles during instruction, learners should first be presented with intermediate abstractions in the form of dynamic causal models. White argues that intermediate abstractions can recruit learners' phenomenological understanding (in the domain of physics) and intuitive knowledge (in general) to help them develop causal explanations, which can then be further refined to develop a more canonical explanation of the relevant phenomenon.

Within DIGs, intermediate abstractions and "intermediate representations" based on those intermediate abstractions can recruit players' intuitive and phenomenological knowledge to help constrain players' interpretations of formal representations (i.e., the Cartesian graphs). This constraining function is valuable because learners commonly conceptualize graphs as iconic representations of real events (Preece \& Janvier, 1992). For example, when viewing a graph of the speed of an automobile, learners may interpret the graph in terms of the position of the automobile on the track and may also erroneously interpret steeper slopes as a higher value instead of a higher rate of change, which is known as slope-height error (Bell \& Janvier, 1981).

The relationship between conceptual knowledge and representational competence has been highlighted in a plethora of studies, which show that learners with low domain knowledge experience greater difficulties with graph comprehension. For example, middle school learners with low prior knowledge about weather maps focused on extracting individual data points, made only superficial interpretations, and rarely integrated information or compared graphical information (Edelson, Gordin, \& Pea, 1999). Similarly, Shah and Shellhammer (1999) demonstrated that novice graph viewers were more likely to interpret line graphs more superficially than experts. In terms of constraining functions, Madden, Jones, and Rahm (2011) found that undergraduate chemistry learners exhibited a 
preference for a single representation at first, but that they used familiar representations to constrain understanding of novel ones after gaining proficiency.

In terms of DIGs, the intermediate representation is typically graphical based on Stenning and Oberlander's (1995) axiom that graphical representations are generally more concrete than analogous textual representations. The constraining function of the intermediate representation should decrease players' tendencies to make common interpretation errors, such as the slope-height error. The intermediate representation should also serves to enhance players' understanding of how graphs are constructed by providing a context for them to construct the graph from the concrete phenomenological view. In terms of DIG examples, players in the Action Potential time-series analysis DIG would aggregate sodium and potassium ions vertically to construct the appropriate formal representations. Similarly, players in the non-time series Cartesian Kinetic Explorer DIG would aggregate the flame icon at different pressure values to create the pressure-versus-time graph. On a more general level, we believe that such exercises can support the development of players' representational competence in DIGs.

\section{Fewest Representations -- Use the Fewest Representations Aligned with the Informational and Computational Properties of the DIG}

Including an intermediate representation is in productive tension, however, with minimizing the total number of representations. The design goals in a DIG involve connecting the phenomenological view of the system to the formal representations so that players can translate within and across representations. Based on the research on intermediate abstractions and the research on the difficulties that learners encounter when interpreting Cartesian graphs, the addition of a constraining intermediate representation is warranted.

Research on displaying variables separately versus integrating multiple variables into a single representation is also in productive tension with minimizing the total number of representations. When multiple representations have unique computational properties they can support complementary processes (Larkin \& Simon, 1987). Computationally non-equivalent representations can reference identical information but differ in the speed and ease with which inferences can be derived (Ainsworth, 2014). Ainsworth, Bibby and Wood (1997) studied elementary aged children learning estimation principles through the CENTS simulation. The children were provided with feedback on the accuracy of their estimation in terms of the direction and magnitude. Children who received feedback through multiple simple representations learned estimation principles faster than children who received feedback through more complex integrated representations.

Balancing these tension, the minimum number of representations based on the informational and computational properties and functions of the DIG includes: (a) a phenomenological representation, (b) one or more formal representations that are potentially further separated at least initially into series of simpler individual representations, and c) intermediate representations that meaningfully hybridize or juxtapose the phenomenological and formal representations.

SURGE Symbolic should therefore include a phenomenological representation, one or more Cartesian graphs of key formal abstractions (e.g., position, velocity, acceleration, force, or mass) as required by each phase of the game, and a dot trace intermediate representation that is overlaid on the world representation (Figure 1). The dot trace places a "dot" on the world representation at fixed intervals in time to track Surge's path in the world view. Dot traces are common in physics classes because they allow students to infer how position is changing over time, which allows the student to then infer how velocity and acceleration are changing over time. Essentially, bigger distances between dots equate to bigger changes in position over time (or velocity). Following from research demonstrating that a series of simpler representations can in some instances be better than a more complex integrated one, SURGE Symbolic uses series of separate position, velocity, and force graphs depending on the focus of a given game level. Similarly, our Action Potential DIG would include the phenomenological simulation view of sodium and potassium ions moving in and out of their respective 
channels across the neuron axon membrane along with intermediate representations aggregating these ions over time. This DIG would also include two separate sodium and potassium ion movement-overtime graphs to assist players in understanding how these ions move individually before understanding their interaction via the membrane potential-over-time graph, the third formal representation for this DIG. The Kinetic Explorer DIG would include the phenomenological simulation view of the ideal gas system along with intermediate representations and three separate formal graphs of the pressureversus-temperature, volume-versus-temperature and volume-versus-pressure relationships.

Across these examples, it is evident that splitting complex graphs into separate ones can be beneficial to acclimating novice players in DIGs and also in multirepresentational systems utilizing similar formal representations. Some phenomena, however, are typically represented with certain variables combined into a single representation. In population ecology (the Alien Zookeeper DIG), for example, a single Cartesian change-over-time graph typically combines both predator and prey populations. How and when to separate versus combine such graphs is explored further in the discussion section. Overall, each representation in these DIG exemplars affords players unique computational information and processes in support of the intended learning goals. Each DIG (or other similar multirepresentational system) may therefore vary in the minimum optimal number of representations.

\section{PARAMETER 2: INFORMATION}

DeFT specifies distribution of information as the second of the five parameters for consideration. Information can be distributed in many ways in multirepresentational environments according to the pedagogical goals of the system.

\section{Redundant Representations - Gradually Reduce Redundant Representations as Users Increase in Expertise}

Hegarty and Just (1993) found that novices presented with drawings of simple pulleys and textual descriptions scored significantly higher on kinematics problems than subjects presented with only the pulley diagrams or the textual descriptions but not on problems assessing their understanding of the configuration of the components in the pulley system. Similarly, Ainsworth, Bibby, and Wood (1997) found that subjects who were given two non-redundant representations learned estimation accuracy faster than subjects given two redundant representations when performing computational estimate tasks. Kalyuga, Chandler, and Sweller (1998), however, found that redundant textual information annotating diagrams enhanced subjects' learning as novices but hindered their learning as the novices became more expert. Thus, redundant representations can be a useful scaffold for novices but should be reduced gradually as users increase in expertise.

Accordingly, all graphs in in SURGE Symbolic and our other exemplars have annotations that appear as the user scrolls across the graph with the relevant information for each data point on the graph (Figure 5). While this information is redundant, it is useful for novices. As players get more advanced in their understanding of the representations in our DIGs, the players or the DIG software can toggle or fade the annotations to mitigate any expertise reversal effects. Similarly, multiple representations of a phenomenon might be of value early in an activity progression to bootstrap and constrain novice players, but these redundant representations should be faded as players' expertise increases.

\section{PARAMETER 3: FORM OF REPRESENTATIONS}

Representations can take a variety of forms that differentially impact how learners process them. Research on the forms of representations in relationship to learning goals provides substantial evidence supporting the view that differences in the form of representations influence learners' cognitive processes and outcomes (Ainsworth, 2006). 

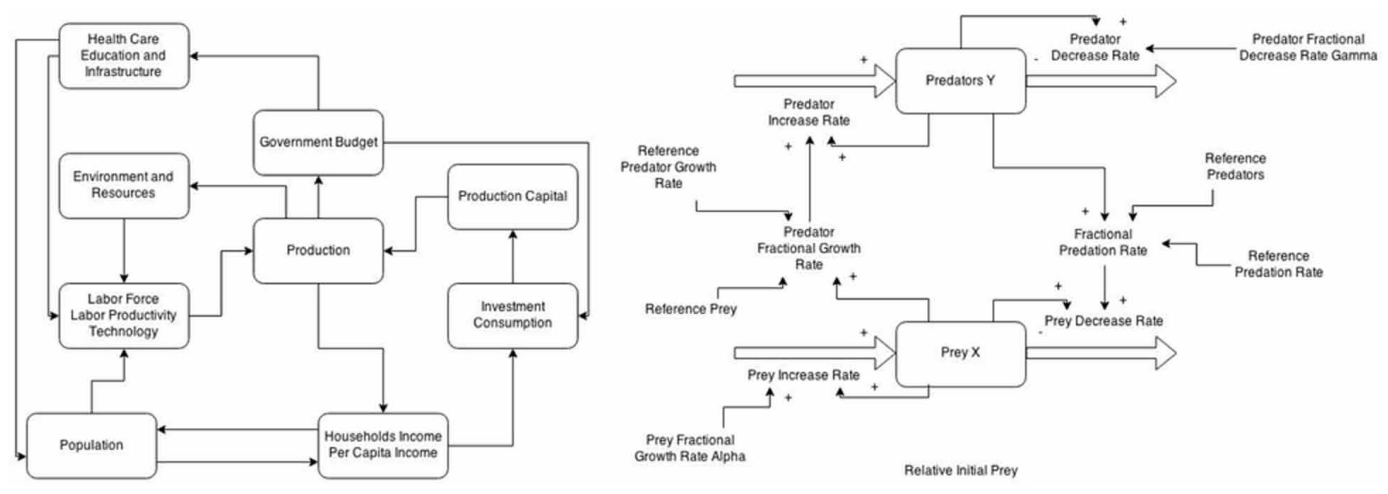

\section{Structural Diversity - Employ Structurally Diverse Representations Aligning with the Pedagogical Goals of the System to Leverage the Cognitive Affordances of Each Structure}

Bibby and Payne (1993) found that subjects learning to use a simple device who studied verbal rules were faster at determining which switches were misaligned than subjects who studied tables and diagrams. Conversely, subjects who studied tables and diagrams were faster at identifying faulty components. Stieff, Hegarty and Deslongchamps (2011) presented subjects with four distinct representations for a molecular mechanics equation across three interactive visualizations: (1) a mathematical equation, (2) a specific numerical example, (3) a graph, and (4) a ball-and-stick visualization of the system. They found that subjects generally selected the most relevant representation of the four for completing various tasks. Jones (1998) found that dynamic and static representations require different operators to understand, elicit different inferences from learners, and can complement each other when presented together. In summary, a variety of studies have demonstrated that complementary representations serve a useful role in promoting unique forms of reasoning relevant to diverse task demands.

Building on this research, SURGE Symbolic presents players with a variety of representations including the phenomenological, intermediate, and formal graphical representations. The phenomenological (world view) representation capitalizes on the computational properties of concrete visual imagery, the intermediate representation capitalizes on the computational properties of the both graphics and symbolic graphs, and the formal graphical representations exploit the computational affordances of symbolic graph-based representations. Players can access and review static images of linked graph and world-view states at their own pace and relate these to the dynamic world-view visualization. Similar diversities of representations are presented in our other DIG exemplars.

\section{Multimodality - Leverage Multimodal Representations where Feasible rather than Visuals and Text Alone}

The modality principle states that people learn more deeply when the words are spoken rather than printed (Kalyuga et al., 1999; Moreno \& Mayer, 1999; Mousavi, Low, \& Sweller, 1995). There is strong support for the modality effect across a wide variety of learning situations (Mayer, 2005c). Ginns (2005) found in a meta-analysis of forty-three studies that learners who learn from instructional materials using graphics with spoken text outperformed those who learn from a graphics with printed text. Paek (2012) found that the presence of audio narration significantly enhanced learning compared to conditions receiving no audio narration in a virtual manipulative to teach basic multiplication.

Bivall, Ainsworth, and Tibell (2011) found that biochemistry graduate learners given haptic feedback based representations of the dynamic process of protein-ligand interaction learned more and had fewer misconceptions than control participants who did not receive these haptic representations. 
Huang, Vea, and Black (2011) found that players who used a force feedback 3D joystick in conjunction with a catapult physics game simulation performed significantly better on kinematics and transfer questions than players who did not use the force feedback joystick. Huang (2013) found an even stronger effect for the force feedback joystick to enhance learning when it was used to prime players' understanding of physics concepts before game instruction began.

This research suggests that the affordances of both audio and haptic interfaces should be integrated into DIGs where feasible. Use of audio may be more beneficial to novice players to narrate the text of self-reflective and explanative prompts and answers, data points, and graph axes. Audio narration should be user-controlled and/or gradually faded, however, to avoid an expertise reversal effect. Audio can also be used to add sound effects to the various aspects of DIG environments, both phenomenological and formal. Similarly, input interfaces that measured the pressure that players apply by pushing could be included for players to specify the amount of force they wish to apply in the SURGE Symbolic. In our chemical reactions DIG, players could receive haptic force feedback whenever molecules form and break bonds, and players in our Coulomb's force simulation could receive force feedback whenever charge spheres repulse or attract each other. Lastly, while training videos are not novel, they are a multimodal representation that is often under-utilized in preparing players for learning how to interact in a multirepresentational environment. Overall, the integration of audio and haptic modalities and multimedia training videos in DIGs and multirepresentational environments in novel ways has the potential to enhance learning.

\section{Parameter 4: Sequence}

The sequence and activity structure around the representations in a multirepresentational system clearly matter. Research on domain-specific versus domain-general approaches to integrating, segmenting, and comparing and contrasting representations is central to thinking about sequencing in DIGs.

\section{Concrete before Abstract - Sequence Concrete Representations Prior to More Abstract Ones, but Domain-Specific Considerations May Supercede}

Ainsworth et al. (1998) advocate for presenting learners first with concrete representations and then gradually presenting more abstract representations. For example, learners in her COPPERS environment were presented first with pictures of coin problems, then a combination of text and pictures, then text in isolation, and then as algebra. Resnick and Omanson (1987) found that children no longer utilized concrete representations (i.e., Diene blocks) after the children had learned to automatically manipulate symbol representations to subtract numbers. New representations should thus be presented before learners have automated their understanding of the current representation (Ainsworth, 2006). Similarly, Plotzner (1995) advocates presenting qualitative representations before quantitative representations when teaching one-dimensional physics problems.

Designers of multirepresentational systems can also implement a continuum of domain-specific approaches to sequencing representations (Ainsworth, 2006). Sometimes these domain- specific approaches may be in tension with the concrete-to-abstract pattern. In Kaput's (1994) MathsCar calculus simulation, for example, Kaput advocates introducing integration before differentiation in calculus teaching (arguably concrete before abstract) and hence advocates presenting velocity graphs before position graphs (arguably abstract before concrete).

Our SURGE Symbolic system sequences representations from most proximal and concrete to more distal and abstract given our disciplinary goals in teaching Newtonian physics. Students are first presented with a worldview visualization, then an intermediate dot trace abstraction, and then formal Cartesian graphical representations, which tend to be most difficult for players. In terms of graphical representations, players begin with only a position graph. Players are then scaffolded through a series of game levels and dot trace intermediary activities to seeing a velocity graph (the integral of the position graph). 
There is tension, though, between the domain-general design consideration of concrete-to-abstract and the domain-specific consideration of starting instead with velocity, which is more easily mapped to the dot trace intermediate representation (which is the archetypal progression in learning about Newtonian mechanics). To further explore these tensions, we are continuing to research approaches to balancing these sequence tensions between domain-general and domain specific in SURGE Symbolic and other DIGs. Thus far, domain-general concrete-to-abstract approaches appear to be productive starting points in our other DIGs. In Alien Zookeeper, for example, players would first explore a concrete predator/prey simulation, then intermediate representations would be added, and finally with the formal graphs of predator/prey populations would be added. In Zookeeper System Dynamics, players would be presented with the zoo simulation prior to viewing nodal feedback graphs of population dynamics. Domain-specific considerations would likely arise, however, as we moved deeper into development, and tensions between domain-general and domain-specific would need to be balanced in a manner similar to the balancing required by all similar multirepresentational systems.

\section{Segmenting - Use predefined or User-Defined Segmenting and Pictorial Scaffolding of Dynamic Visualizations to Foreground Critical Points and States}

We next consider research on static and dynamic displays of information. Dynamic visualizations often preclude learners from re-inspecting information, which reduces their efficacy (Hegarty, 2004). Mayer, Mautone, and Prothero (2002) found that learners who viewed pictorial scaffolds highlighting key states in a geology simulation learned more than learners who did not view the scaffolds or learners who viewed verbal scaffolds. Mayer, Dow and Mayer (2003) found that learners shown a segmented animation explaining how electric motors worked performed better on transfer questions than learners who watched a continuous animation. Mayer and Chandler (2001) found learners who viewed a segmented animation of lightning formation performed better on tests of problem-solving and transfer than those who viewed a continuous animation. Hastler et al. (2007) found that learners who studied a pre-segmented or user-controlled animation on the causes of day and night learned better than learners who watched a continuous, non-user controlled animation. Segmentation can also serve to define event boundaries for the learner ahead of time (Spanjers \& Van Merrienboer, 2010). Catrambone (1995) found that learners who viewed a series of calculation steps where each step was labeled and/or on a separate line learned better than learners who viewed the calculation steps without segmenting or cueing.

Accordingly, as the player scrolls to each point on the position, velocity and force graphs in our exemplar SURGE Symbolic DIG, the corresponding frame appears in the world-view. In the Alien Zookeeper DIG, the predatory and prey graph is linked frame by frame to the zoo simulation and in the Coulomb's Force DIG, the Coulomb's force over distance square and q1*q2 graphs are linked to the charge sphere simulation. Hence across our DIG examples, the dynamic world-view visualizations are linked to the graphs, frame by frame, and segmented into a series of user-controlled static pictures to scaffold and constrain understanding of the graphs. Users can also pause, fast forward, rewind, stop, and replay the world-view animation using simple controls as much as they like. This design consideration should benefit non-game based multirepresentational systems with similar representations as well. Since this feature is entirely user controlled, users can use it less frequently as they gain expertise, avoiding the expertise reversal effect.

\section{Construction - Delay the Articulation of Abstract Rules and Relationships Until Players Have had a Chance to Construct and Articulate These Abstractions for Themselves Through Comparing and Contrasting}

Rittle-Johnson and Star (2007) found that 7th graders who compared and contrasted alternative algebra solutions achieved greater gains in procedural knowledge and flexibility compared to learners who reflected on alternative solutions one at a time. Rittle-Johnson, Star, and Durkin (2012) found that novice 8 th graders who compared multi-step equation problem solving procedures were more flexible 
problems solvers than those who did not. Similarly, Schwartz, Chase, Oppezzo, and Chin (2011) found that learners who had to invent density formulas after examining contrasting cases performed better on ratio structure and transfer problems than learners who were told these formulas before examining contrasting cases. These studies therefore align with other research advocating the benefit to learners of exploring relationships before being provided with abstract articulations of those relationships.

Across all DIG examples, players use comparisons to invent abstractions in many ways. For example, players create graphs and then compare and contrast across them. As players complete a trial, they will be able to see and compare the results of this past trial transparently as they perform a new one. Other forms of comparing and contrasting occur when players are prompted to compare more than one graph on the screen (e.g., a position communication graph and a velocity control graph in SURGE Symbolic or sodium ion and potassium ion intracellular concentration-over-time graphs in our Action Potential DIG). Across DIGs, prompts encourage players to explore how both graphs are similar and different and to try to form relations among the two using the various segmenting activities at their disposal.

Players also have "sandbox" levels, where they are free to explore and make their own graphs and compare them across trials to make their own inferences. Providing learners with opportunities to invent abstract rules is a powerful principle to apply to designing non-game based multirepresentational systems as well.

All DIGs therefore focus on scaffolding players' exploration of relationships within and across representations. The goal involves supporting players in exploring the relationships first to develop a tacit phenomenological understanding and then eventually to explicitly articulate the underlying relationships through the game dialog interface with the game characters. This process of exploration, invention, and articulation would also extend to other multirepresentational environments with similar intended functions.

\section{PARAMETER 5: TRANSLATIONAL ACTIVITIES}

Learners can integrate information from multiple representations to construct a deeper understanding than would be afforded by individual representations. This process is known as translation (Ainsworth, 2006). Learners are more likely to transfer the deeper understanding achieved through integration of representations to new domains and situations (Bransford \& Schwartz, 1999). Stull, Hegarty, Dixon, and Stieff (2012), for example, found that learners who interacted with physical models translated more easily between diagrams of molecular structure. Furberg, Kluge, and Ludvigsen (2013) found that the provision of science diagrams of heat and transfer promoted the coordination, discussion, and interpretation among groups of learners. The following sections synthesize design considerations for supporting translation across representations in DIGs in terms of research on dynamic linking, signaling, and explanation prompts within game dialog.

\section{Dynamic Linking - Structure Environments so that Players Construct Dynamic Links and Embodied Connections Across Representations}

Dynamic linking occurs when learners interact with one representation and see the corresponding results in another. SimCalc, for example, dynamically links actions in one representation to other representations in a simulation environment designed to teach the mathematics of change (Hegedus \& Roschelle, 2013). Kaput (1992) specifically argues that dynamic linking is particularly beneficial when the representations are expressing action sequences opposed to merely final outcomes.

Van der Meij and de Jong $(2006,2011)$ explored learners' understanding of the turning effect of a force, known as the moment, using abstract equations and graphs dynamically linked to concrete animations and numeric representations. Domain knowledge was significantly improved in the dynamically linked integrated display condition compared to the separated non-linked display condition. Subjects in the integrated dynamically linked condition also found the representational 
system easier to use, interpret, and manipulate. Furthermore, Van der Meij and de Jong (2006, 2011) found that (a) dynamic linking supported learners in constraining representations but (b) dynamic linking did not support additional translation beyond that.

Research has demonstrated that dynamic linking should be varied based on the level of learners' prior knowledge. Van Labeke and Ainsworth (2003) studied three learners' use of multirepresentational software and found that learners with low prior knowledge used dynamic linking to relate representations superficially while learners with higher prior knowledge used dynamic linking less and related representations on deeper levels. Ainsworth (2006) concluded from this study that the degree of support as well as the level at which it is provided should be varied based on the prior knowledge of the learner. Ainsworth (2006) further cautions that over-automation of relating representations may discourage learners from reflecting on the nature of connections among representations.

Research on embodied or perceptually-grounded cognition can ground our understanding of effective dynamic linking. Furthermore, these perspectives reinforce the multimodality design consideration discussed in the previous section. Embodied cognition research posits that achieving a full understanding of a concept entails being able to create a mental perceptual simulation of it when retrieving or reasoning about the concept (Barsalou, 2008, 2010; Black, 2010). Mokros and Tinker (1987) and Brasell (1987) found that children using motion sensors to create graphs of position and velocity demonstrated significant gains on graph interpretation. Chan and Black (2006) found directly manipulating interactive kinematics animations improved learning for these concepts. Yang, Black and Jyung (2010) found that medical learners who interacted with a 3D internal anatomical structure via a joystick that allowed them to rotate the structure comprehended the structure better than learners who simply viewed an identical video of the 3D structure. Bodemer, Ploetzner, Feuerlein, and Spada (2004) found learners who had to actively integrate textual and algebraic representations in a statistics simulation by dragging and dropping them in the appropriate location performed better than learners who did not integrate them or viewed a split source representation.

Accordingly, we are working to develop a variety of functionalities in SURGE Symbolic and other DIGs that will support a more embodied perspective for players. In terms of existing functionality, embodied activities already dynamically link and constrain our concrete world-view and physics graphs in more active ways. The player can, for example, drag and manipulate thrusters of various magnitudes, durations, and directions on the force graph across various time points (Figure 6). This is a more embodied way of constructing the force graph that applies to constructing graphs in other DIGs and non-game multirepresentational systems.

In terms of functionality under development, players in future versions of SURGE Symbolic will click on dots to form line segments from the dot trace they have just created, and they will then manipulate these line segments to construct their graphs of velocity and position (Figure 7). Similar

Figure 6. User controlled force thruster
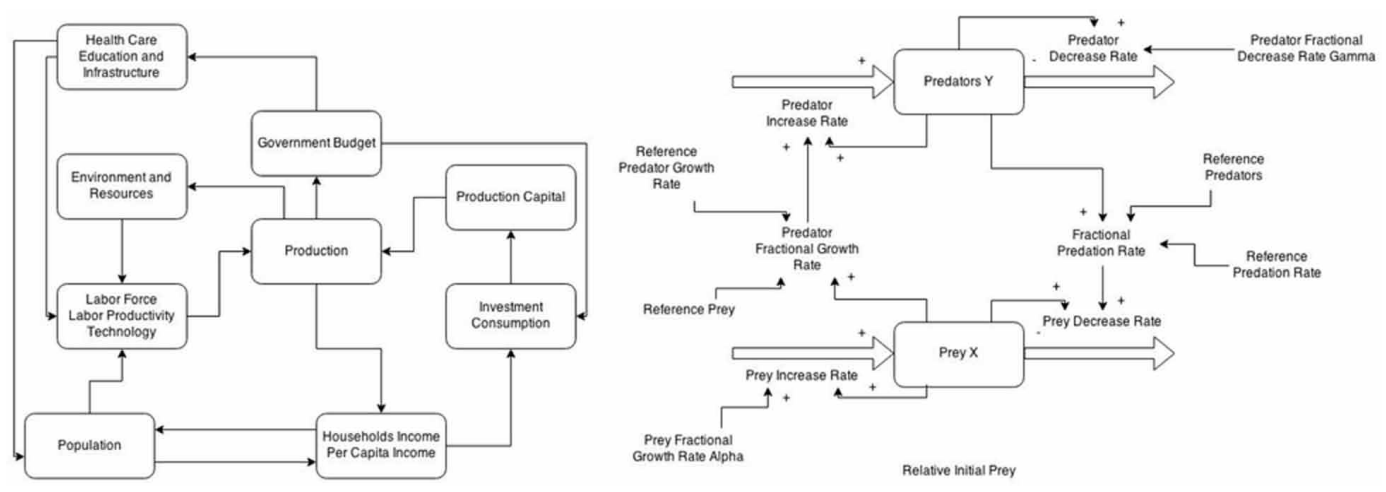
Figure 7. Dot trace position line segment

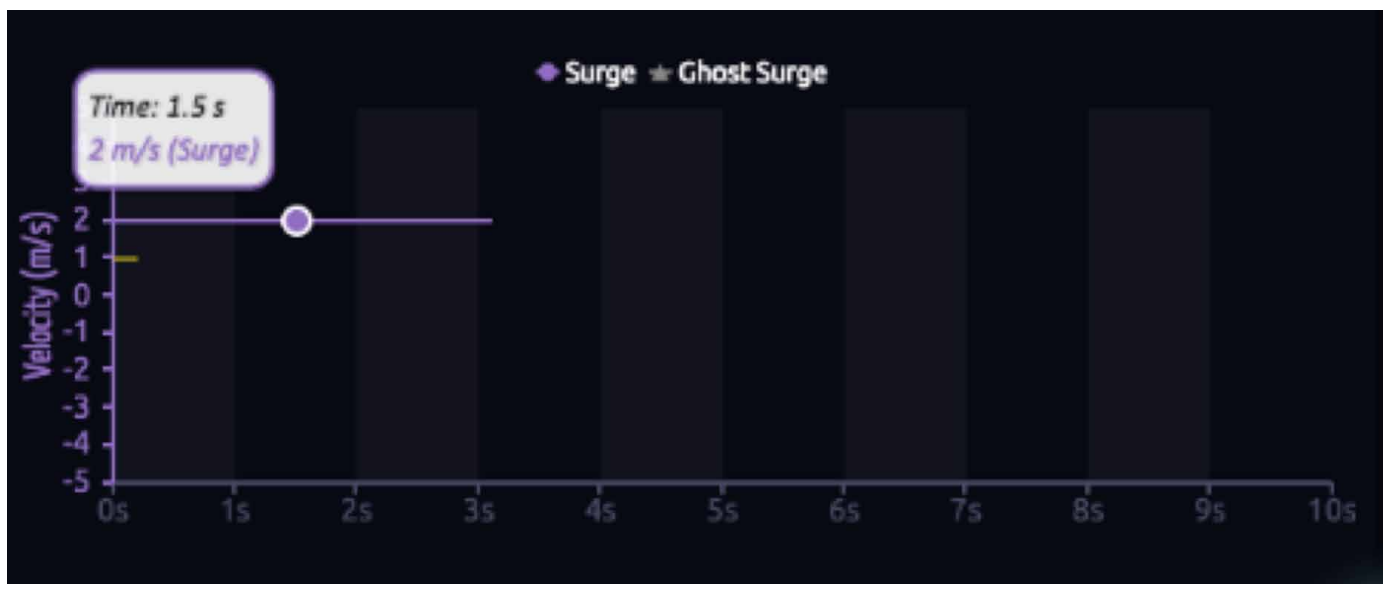

embodied aggregating activities will be explored for other DIGs. As players increase in expertise, this process will be automated and then faded completely. We are also working to develop functionality in SURGE Symbolic so that users can drag their mouse along a user-defined segment of a graph, release the mouse, and then see an animation of Surge's motion for that segment.

All such translational activities should adapt to both player expertise and optimal depth of instruction. As the learner progresses, DIGs and other multirepresentational environments should gradually transition from superficial to deeper translational activities to link across formal representations.

\section{Signaling - Use Signals Including Congruent Axes, Numbers, Labels, and Scales Across Representations}

Learners comprehend more when multimedia presentations are signaled (Mautone \& Mayer, 2001). Signaling is the process of using cues to direct a learner's attention towards key events in a multimedia presentation and the causal relations among these events. Mautone and Mayer (2001) found that learners presented with a signaled presentation on how airplanes achieve lift performed significantly better on transfer questions than learners who viewed the non-signaled version. Signaling in static illustrations was found to direct learners' attention and enhance learning (Tversky et al., 2008). Signaling can be implemented in multiple forms to help learners perceive relationships among representations, such as altering the luminance of objects in a display (e.g., De Koning, Tabbers, Rikers, \& Paas, 2007), altering font style (e.g., Mautone \& Mayer, 2001), flashing elements (Craig, Gholson, \& Driscoll, 2002; Jeung, Chandler \& Sweller, 1997), and orienting gestures guiding learners to related elements (Lusk \& Atkinson, 2007). Not all forms of signaling work equally well in all instructional contexts. Hegarty, Kriz, and Cate (2003) found, for example, that arrows signaling important steps and causal chains of events in learning how a flushing cistern works did not benefit learners. Signals should be carefully designed in light of the intended function, the expertise of the learners, and the nature of the relationships highlighted.

When representations have consistent labels and similar colors to represent similar objects across representations it is easier for learners for perceive the relationships among them (Ainsworth, 2006). Children, for example, tend to recognize that representations relate to the same problem only when they use the same numbers (Dufour-Janvier et al., 1987). Zhang (1996) advocates the importance of matching the scale of the representation of information to the scale of the display of this same information. Specifically, he states this will avoid over-interpretation of representations with nominal information displayed using interval scales or increased cognitive load of understanding 
representations with interval information displayed using nominal scales. Ainsworth (2014) generalizes these assertions to the principle that when distributing information over multiple representations it is beneficial to match the scales of the information and the display.

In SURGE Symbolic (Figure 8) and all of our other DIG exemplars, the same X-axis time scale is used across all graphs to maximize similarity across them. When possible, the Y-axes across graphs and the world-view use similar interval scales. When graphs and the phenomenological view are being compared in the various DIG exemplars, similar colors and flashing are used to signal which slope segments on graphs and which segments of the world-view are being compared and translated. Accordingly, utilizing similar axes and signaling relationships among representations can be beneficial across DIGs and most multirepresentational systems.

\section{Explanation Dialog - Use Adaptive Self-Reflective and Explanative Feedback Prompts in Game Dialog to Scaffold Players to relate Specific Elements within and between Representations}

Roy and Chi (2005) found that self-explanation fosters average learning gains of $20 \%$ in learning from multimedia presentations, $44 \%$ for learning from diagrams, and $22 \%$ for learning from text. Explanative feedback prompts require learners to choose an answer to a question and then give them

Figure 8. Segments of graphs flashing to signal translation

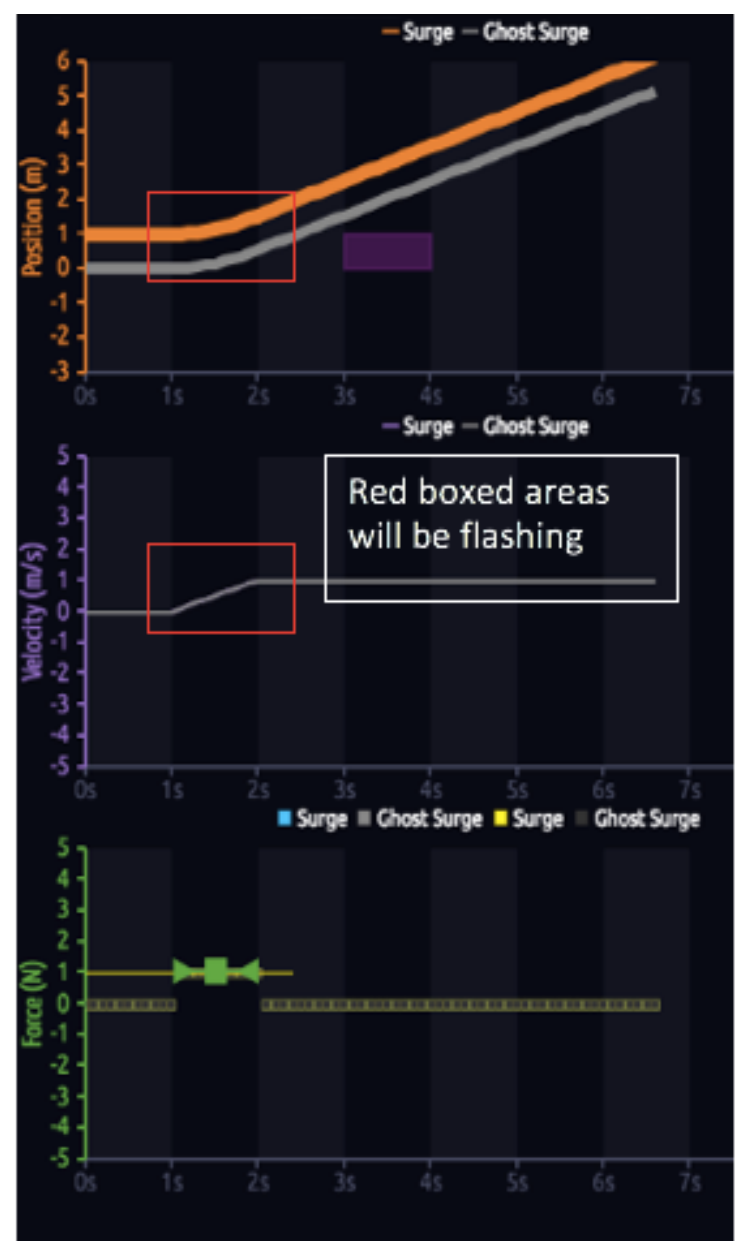


an explanation for the correct answer choice. Moreno and Mayer (2005) found that learners who received explanative feedback prompts while playing the Design-a-Plant game learned better than learners who received simply corrective feedback or no feedback whatsoever. Also, they found that reflection was most useful for enhancing learning in interactive environments when learners reflect on correct answers opposed to their own solutions. Mayer and Johnson (2010) found that learners playing a circuit game who received self-explanation prompts for embedded game questions where they had to choose the correct circuit principle from a list, received explanative feedback after choosing an answer from a list, or both performed better on transfer questions than learners who received no self-explanative or explanative feedback. Importantly here, learners chose an explanation from a list and did not generate explanations spontaneously.

Berthold and Renkl (2009) found that self-explanation prompts that encouraged learners to integrate parts across different representations assisted learners in acquiring conceptual knowledge in a multirepresentational simulation environment about probability. They also found, however, that incorrect self-explanations hindered the acquisition of procedural knowledge. Van der Meij and de Jong (2011) provided learners with more specific and directive self-reflective scaffolding prompts to translate and relate representations in a multirepresentational physics environment. They found that these directive prompts enhanced learners' domain knowledge significantly more effectively than general self-reflective prompts.

Cognitive flow is also an important consideration when designing prompts. Flow experiences include periods of concentration, distorted time, and an enhanced sense of control (Kiili, 2005; Adams \& Clark, 2014). Adams and Clark (2014) found that middle school learners who received explanative prompts performed slightly worse than learners who did not receive prompts in a physics game environment. Adams and Clark hypothesized that this occurred because learners were overloaded, and their game flow was disrupted, by the timing and number of questions as well as the fact that learners were required to reflect upon incorrect as well as correct answer choices. Hsu, Tsai, and Wang (2012) divided learners into high and low engagement level learners based on their ratio of correct, incorrect, and "I don't know" responses to self-explanation prompts (which learners received each time they made a mistake in an educational game about shadows). High engagement learners scored significantly better on comprehension tests than low engagement self-explanation learners, emphasizing the importance of users' engagement and motivation with prompts.

There is also substantial literature indicating that adaptive feedback can enhance learning. Chi et. al (2011) found that adaptive learning systems for teaching introductory college physics improved learners' learning gains significantly. Reif and Scott (1999) compared human tutoring, step-based tutoring, and no tutoring for a physics domain. They found that gain scores between human tutors and step-based tutors were not significantly different, but were significantly better than having no tutor. VanLehn (2011) found intelligent computerized tutors that adapted content according to learner performance were even more effective than human tutors.

Accordingly, SURGE Symbolic engages players with explanative prompts within the game dialog. Figure 2 presented an example where dialog choices are presented as text. Figure 9 presents an example where the dialog choices are presented as images (graphs in this example, but dialog choices in the system can include any combination of text and images). Corrective feedback prompts are not used, instead explanative feedback prompts occur in the dialog only after players have successfully completed a specific challenge that exemplifies the relationships at the heart of specific explanative feedback prompts. Further explanations are provided based on the explanation selected by the player.

In SURGE Symbolic, for example, a computer character may ask players to relate a plateau in a multi-step velocity graph to a specific constant increase in slope in the position graph. In our Coulomb's Force DIG, players may relate the center of the force-versus-distance-squared graph to the center slope of the $\mathrm{q} 1 * \mathrm{q} 2$-versus-force graphs to encourage players to explore and articulate how exponential and multiplicative forces are related. These prompts emphasize translation by asking players to relate the phenomenological representation to broad and specific segments of the formal 
Figure 9. Explanative scaffolding prompts with images for dialog choices

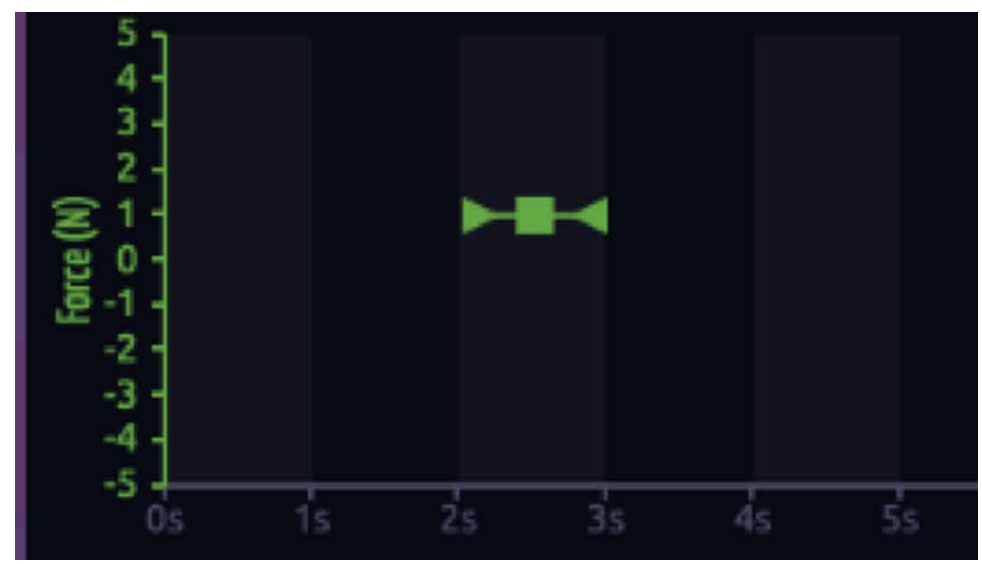

graphs as well as to relate specific parts of representations between and within representations. Such prompts are useful in both the design of DIGs and most multirepresentational systems. Across our exemplars, the explanative and self-reflective prompts adapt to player expertise in three ways: (1) prompts increase in difficulty and specificity as players perform better on them, (2) more prompts are given to players for concepts they consistently perform poorly on, and (3) prompts appear less frequently once players progress further along the game and have demonstrated expertise to avoid an expertise reversal effect. This adaptive framework is highly applicable to other multirepresentational systems. Furthermore, the explanative and self-reflective prompts should be integrated into a story arc to enhance engagement. Overall, a variety of story arcs across DIGs should be used to encourage players to feel empowered that their translational actions will help achieve key game objectives for the main characters.

\section{DISCUSSION}

The current paper has applied the DeFT framework (Ainsworth, 2006) as a lens to synthesize design considerations for disciplinarily-integrated games. In addition to the literatures on single and multiple representations, we have leveraged the literatures on embodied cognition, segmenting, signaling, comparing and contrasting, adaptive scaffolding, and learning from dynamic visualizations to address the challenges, tradeoffs, and questions highlighted by the DeFT framework. Applying the proposed design considerations to DIGs across model types and modeling strategies was demonstrated as generally clean and consistent in terms of the proposed examples. We thus propose that most of the design considerations should transfer well to other DIGs based on those model types and templates, and potentially beyond to DIGs and other multirepresentational systems with similar intended functions based on other model types and modeling strategies outlined. There are three issues arising from the application of the design considerations to DIGs, however, that raise important issues meriting further discussion, exploration, and research: (a) the potential efficacy of shifting so much control to the player, (b) balancing design considerations, learning goals, and game mechanics, and (c) the relative tradeoffs in combining versus separating variables in graphs.

\section{Equivocal Research about the Benefits of User Controls in Multiple Representation Systems}

Research demonstrates that user control can contribute substantially to learning. Subjects presented with an animation where they could interactively control the pace of an animation about lightning 
formation, for example, performed significantly better than subjects who had no user control (Mayer \& Chandler, 2001). Furthermore, Ainsworth (2006) makes clear that over-automating connections across representations can diminish their efficacy. Research has found, though, that full user control of dynamic media is not always beneficial. Kriz and Hegarty (2004), for example, found that high prior knowledge learners, but not low prior knowledge learners, could construct models of a novel device after viewing user-controlled animations. Similarly, Lowe (2003) found novices interacting with user-controlled animations of a weather map focused on perceptually striking features instead of thematically relevant ones.

SURGE Symbolic and other DIGs, however, have user-controlled visual environments that are structured differently than the environments in Kriz and Hegarty (2004) and Lowe (2003). Specifically, the user-controlled visualizations in those studies were not generated by the learner. Players in DIGs and other multirepresentational systems with similar intended functions actively make choices that affect the outcome in the representations. Players use controls specifically to explore and understand the implications of their actions so that they can solve the current or future levels more effectively. As discussed in Clark et al. (2015), the studies we have conducted thus far with the SURGE series of games suggest that user-controls can support deeper engagement and exploration of the relationships depicted within and across representations.

Also, as discussed in the appropriate design consideration sections, user controls in DIGs are integrated with (a) pre-segmented areas, (b) signals to help players attend to thematically relevant features within and across representations, and (c) translational activities and prompts to construct and bridge representations. Accordingly, these additional features should promote the efficient use of user-controls by the player, especially when the players are novices, but this requires further exploration. Overall, the tension over degree of user control highlights the importance of the design of control systems (in DIGs or other multirepresentational systems with similar intended functions) such that mechanics support translational activities rather than random trial-and-error line fitting or other brute force strategies.

\section{Balancing Design Considerations, Intended Learning Goals, and Game Mechanics}

A second critical tension involves balancing design considerations, intended learning goals, and game mechanics. Examining the design considerations about intermediate representations and the dynamic linking, for example, highlights the challenge of designing the translational activities with intermediate representations so that they are less artificial and more tightly integrated into the game mechanics of the DIG. When players create line segments out of the dot trace and drag these line segments to create the position and velocity graphs and link them to the phenomenological world view in SURGE Symbolic, or when players perform aggregating activities to link ion concentrations in our action potential and chemical reactants DIG examples, how can these translation/construction activities be structured as central and engaging game mechanics rather than mandatory tasks that must be completed to allow further progress? Similarly, examining the design consideration about self-explanation, we have found a strong tension between the learning mechanics and the flow and engagement of the game mechanics (e.g., early work on explanation in SURGE by Adams and Clark, 2014). Optimally, the explanation functionality should be woven into engaging game dialog with characters in the game, but ongoing research and design will be required to achieve this goal.

An early math game from the 1980s called MathBlasters is often invoked to highlight this tension in educational game design. In MathBlasters, players complete school tasks (i.e., solve math problems) to earn the right to subsequently shoot junk and trash in space. Thus, the engaging game mechanics (shooting junk in space) is separate from the learning mechanic (solving math problems). Habgood and Ainsworth (2011) and others describe this distinction as extrinsic integration (when the game and learning mechanics are separate) and intrinsic integration (when game and learning mechanics are one and the same). Clark and Martinez-Garza (2012) point to a more stringent case of intrinsic integration that they define as conceptual integration. While Habgood and Ainsworth 
(2011) and others have demonstrated that intrinsic integration is possible and can increase both learning and engagement, successfully designing for intrinsic integration is much more challenging than designing for extrinsic integration. Future research on DIGs and other games for learning needs to focus carefully on these questions.

\section{Combining Versus Separating Variables in Graphs}

A third important (but finer-grained) issue involves the tension between combining variables in graphs versus exploring each variable in a separate representation. When are iconic formal representations depicting multiple variables on the same graph beneficial for novice players? When and how might the individual variables be more productively distributed across separate representations? For example, prototypical predator/prey population-over-time graphs present both the predator and prey variables on the same graph (Figure 3). Iconic action potential graphs similarly display changes in sodium and potassium ions over time on the same graph. Following from the design consideration of including the fewest representations, having separate representations for each variable may overload novices. Alternatively, splitting such graphs into two separate graphs and then giving players translational activities to construct graphs comparing both variables simultaneously may be optimal and most aligned with the pedagogical goals of the system under design considerations of structural diversity. In SURGE Symbolic, for example, the various position, velocity, and acceleration graphs depicting motion are separated but utilize the same $\mathrm{X}$-axes for time. This approach does not violate design considerations of fewest representations, because these additional isolated representations are not extraneous to learning and may in fact be essential for novice players.

Some phenomena of interest, however, focus on the pattern of displacement of the variables, which requires direct overlaying and comparison of the variables in a single representation. In the case of the population-prey graph, for example, the sin-waves are only slightly offset. Placing the predator and prey variables in separate graphs occludes this relationship. Furthermore, it may be valuable to familiarize players with the formal disciplinary representation of the phenomenon. Thus, ultimately the variables may need to be displayed in the same graph (which aligns with Mayer's contiguity principle) so long as the axes are commensurable for each variable (e.g., predator and prey graphs use the same Y-axis - population - whereas the velocity and position graphs do not). Following from the design considerations, however, the variables should potentially be treated separately initially to support the player in developing an understanding of each individual graph before overlaying the graphs (if they are commensurable). How best to scaffold players to this point remains an open question.

\section{IMPLICATIONS AND FINAL THOUGHTS}

While the issues discussed above require further exploration and consideration, we propose that DIGs and the design considerations discussed in this paper provide a generalizable genre and template. Furthermore, we propose that DIGs and the associated templates and design considerations hold promise as vehicles for engaging players with key model types and modeling strategies that cross multiple disciplines and respond to calls for greater emphasis on problem-solving, 21st century skills, and engaging players in the practices of disciplines to develop deeper understanding. We now close the paper by considering the implications of this generalizability.

\section{Why are the Design Considerations of Value?}

The design considerations synthesize research across broad areas of cognitive science including multirepresentational learning, embodied cognition, multimedia learning, and spatial cognition. Hence, these considerations exemplify how varied areas of cognitive science can be synthesized cohesively to inform instructional design. Additionally, research in multirepresentational gaming is sparse, and these design considerations therefore provide a useful template for how to apply such varied learning principles to the design of educational games involving representations. Furthermore, 
many of the design considerations extend beyond DIGs to inform the design of non-game based multirepresentational systems with similar intended functions across a diversity of contexts. These considerations help frame the various complementary, constraining, and constructing roles potentially afforded by representations and structures in multirepresentational systems more generally.

The design considerations are not absolute and are, in fact, "considerations." Accordingly, they provide a formulation for researchers to assess in terms of their applicability across a spectrum of designs, contexts, learners' prior knowledge, spatial and verbal working memory capacities, attentional capabilities, motivational levels, age, gender, sociocultural environment, and many other factors. Also, as Ainsworth and others (e.g., Clark, Tanner-Smith, \& Killingsworth, 2016) make clear, studies of multirepresentational systems and studies of digital games for learning typically do not provide detailed articulations of the intended functions of the representations and activity structures under study, nor do they typically provide detailed articulations of the specific designs enacted to support those intended functions. Ainsworth (2014) and Clark, Tanner-Smith, \& Killingsworth (2016) make clear that such theoretical articulations are necessary for research and fields to move beyond simple comparisons to meaningfully explore deeper questions of how specific designs and structures can be leveraged to achieve intended functions for specific learners.

Furthermore, these design considerations are intended not only for researchers but also for designers in industry. For example, simulation designers for engineering companies and military training facilities may benefit from these design considerations depending on the intended functions of their multirepresentational systems. Multi-representational systems are increasingly prevalent, especially in virtual and augmented reality (AR) environments. AR interventions require overlaying formal representations onto the phenomenological real world surrounding learners. Accordingly, these design considerations could help AR designers consider approaches for overlaying formal representations and actively engaging learners in translating across formal and real-world representations.

Overall, these design considerations may thus (a) help synthesize synergistic areas of research on cognition, (b) apply to many learning environments within and beyond educational games, and (c) highlight interesting questions for further research.

\section{Economically Feasible Propagation of Games in the Curriculum}

Up to now, the task of developing digital games for learning in multiple disciplines at an economically feasible budget has often devolved into simple forms of gamification (i.e., simply layering points and badges over mechanics that are not themselves game-like). On the other hand, creating a game where core disciplinary ideas drive game-mechanics has proven time-intensive and cost-intensive. This, in turn, has created an obstacle to the systematic integration of digital games across the curriculum. A potential advantage of the generalizability of the DIG genre and the proposed design considerations proposed is that, once a DIG template is honed and refined through iterative cycles of design and research, designers can build on the same conceptual, functional, design, and software foundations to create other DIGs in other disciplines. The proposed genre, templates, and design considerations could therefore create important economies of scale in terms of development time and cost for integrating games systematically across the curriculum.

\section{Beyond Learning Within the Game: Development Across the Curriculum}

Even more importantly, this generalizability has critical implications for the development of learners themselves across the curriculum. Much research on digital environments in the classroom has focused at the level of the activity rather than the level of the longer-term curriculum because of limitations in technology development. However, the conceptualization of DIGs as multirepresentational systems lends itself well to thinking about the connections between the curricula beyond DIGs in terms of the epistemic and representational forms therein. 
The "science as practice" perspective attends to the long-term production of scientific knowledge through the long-term development of epistemic and representational practices. Typically, however, learners in a K12 science classroom learn small amounts about myriad different domains during the same academic year, thereby minimizing opportunities of meaningful long-term engagement within a single curricular unit. By considering the epistemic and representational forms within each unit, though, DIGs could be interspersed throughout the academic year in order to meaningfully connect across the preceding and succeeding curricular units. Within a DIG, the multirepresentational systems can be designed to enable players to become familiar with a representational form, develop intermediate representations, and then generate new representational forms that are not only canonically more sophisticated, but can also provide representational forms that are leveraged in the subsequent curriculum.

In their strongest form, therefore, DIGs and these design considerations can help us conceptualize the year-long science curriculum as a careful assembly of curricular units, arranged to encourage meaningful connections between epistemic and representational forms. For student learning, it shifts the focus from thinking about learning within a game - i.e., a short-term focus on learning - to the development of epistemic and representational practices that are central to the long-term development of scientific expertise in an authentic manner, i.e., in a manner that is representative of the professional practice of scientists.

\section{ACKNOWLEDGMENT}

This material is based upon work supported by the National Science Foundation under Grant No. 1119290. Any opinions, findings, and conclusions or recommendations expressed in this material are those of the author(s) and do not necessarily reflect the views of the National Science Foundation. 


\section{REFERENCES}

Adams, D., \& Clark, D. B. (2014). Integrating self-explanation functionality into a complex game environment: Keeping gaming in motion. Computers \& Education, 73, 149-159. doi:10.1016/j.compedu.2014.01.002

Ainsworth, S. (2014). The Multiple Representation Principle in Multimedia Learning. In R. Mayer (Ed.), The Cambridge Handbook of Multimedia Learning (2nd ed., pp. 464-486). Cambridge University Press. doi:10.1017/ CBO9781139547369.024

Ainsworth, S. E. (2006). DeFT: A conceptual framework for considering learning with multiple representations. Learning and Instruction, 16(3), 183-198. doi:10.1016/j.learninstruc.2006.03.001

Ainsworth, S. E., Bibby, P. A., \& Wood, D. J. (1997). Evaluating principles for multi-representational learning environments. Paper presented at the 7th European Conference for Research on Learning and Instruction, Athens.

Ainsworth, S. E., \& Van Labeke, N. (2004). Multiple forms of dynamic representation. Learning and Instruction, 14(3), 241-255. doi:10.1016/j.learninstruc.2004.06.002

Ainsworth, S. E., Wood, D., \& O'Malley, C. (1998). There is more than one way to solve a problem: Evaluating a learning environment that supports the development of children's multiplication skills. Learning and Instruction, 8(2), 141-157. doi:10.1016/S0959-4752(97)00013-3

Barsalou, L. W. (2008). Grounded Cognition. Annual Review of Psychology, 59(1), 1-21. doi:10.1146/annurev. psych.59.103006.093639 PMID:17705682

Bell, A., \& Janvier, C. (1981). The interpretation of graphs representing situations. For the Learning of Mathematics, 2(1), 34-42.

Berthold, K., Eysink, T. H., \& Renkl, A. (2009). Assisting self-explanation prompts are more effective than open prompts when learning with multiple representations. Instructional Science, 37(4), 345-363. doi:10.1007/ s11251-008-9051-z

Betrancourt, M. (2005). The animation and interactivity principles in multimedia learning. In The Cambridge handbook of multimedia learning (pp. 287-296).

Bibby, P. A., \& Payne, S. J. (1993). Internalization and the use specificity of device knowledge. Human-Computer Interaction, 8(1), 25-56. doi:10.1207/s15327051hci0801_2

Bivall, P., Ainsworth, S., \& Tibell, L. A. E. (2011). Do Haptic Representations Help Complex Molecular Learning? Science Education, 95(4), 700-719. doi:10.1002/sce.20439

Black, J. B. (2010). An embodied/grounded cognition perspective on educational technology. In M. S. Khine \& I. Saleh (Eds.), New science of learning: Cognition, computers and collaboration in education. New York: Springer. doi:10.1007/978-1-4419-5716-0_3

Bodemer, D., Ploetzner, R., Feuerlein, I., \& Spada, H. (2004). The active integration of information during learning with dynamic and interactive visualisations. Learning and Instruction, 14(3), 325-341. doi:10.1016/j. learninstruc.2004.06.006

Bransford, J. D., \& Schwartz, D. L. (1999). Rethinking transfer: A simple proposal with multiple implications. Review of Research in Education, 24, 61-100.

Brasell, H. (1987). The effect of real-time laboratory graphing on learning graphic representations of distance and velocity. Journal of Research in Science Teaching, 24(4), 385-395. doi:10.1002/tea.3660240409

Catrambone, R. (1995). Aiding subgoal learning: Effects on transfer. Journal of Educational Psychology, 87(1), 5-17. doi:10.1037/0022-0663.87.1.5

Chan, M. S., \& Black, J. B. (2006). Direct-manipulation animation: Incorporating the haptic channel in the learning process to support middle school students in science learning and mental model acquisition. In Proceedings of the International Conference of the Learning Sciences. Mahwah, NJ: LEA.

Chi, M., VanLehn, K., Litman, D., \& Jordan, P. (2011). Empirically evaluating the application of reinforcement learning to the induction of effective and adaptive pedagogical strategies. User Modeling and User-Adapted Interaction, 21(1-2), 137-180. doi:10.1007/s11257-010-9093-1 
Clark, D. B., Sengupta, P., Brady, C., Martinez-Garza, M., \& Killingsworth, S. (2015). Disciplinary Integration in Digital Games for Science Learning. International STEM Education Journal, 2(2), 1-21. doi:. Retrieved from http://www.stemeducationjournal.com/content/pdf/s40594-014-0014-4.pdf10.1186/s40594-014-0014-4

Clark, D. B., Sengupta, P., \& Virk, S. S. (2016). Disciplinarily-integrated games: Generalizing across domains and model types. Chapter. In D. Russell \& J. Laffey (Eds.), Handbook of Research on Gaming Trends in P-12 Education (pp. 178-194). Hershey, PA: IGI Global. doi:10.4018/978-1-4666-9629-7.ch009

Clark, D. B., Tanner-Smith, E., \& Killingsworth, S. (2016). Digital games, design, and learning: A systematic review and meta-analysis. Review of Educational Research, 86(1), 79-122. http://rer.sagepub.com/content/86/1/79. full.pdf+html. doi:10.3102/0034654315582065 PMID:26937054

Clark, D. B., Virk, S. S., Sengupta, P., Brady, C., Martinez-Garza, M., Krinks, K., \& D’Angelo, C. M. et al. (2016). SURGE's evolution deeper into formal representations: The siren's call of popular game-play mechanics. International Journal of Designs for Learning, 7(1), 107-146. Retrieved from https://scholarworks.iu.edu/ journals/index.php/ijdl/article/view/19359

Clement, J. (1985, July). Misconceptions in graphing. In Proceedings of the Ninth International Conference for the Psychology of Mathematics Education (Vol. 1, pp. 369-375). Utrecht, The Netherlands: Utrecht University.

Collins, A. (2011). A study of expert theory formation: the role of different model types and domain frameworks. In Models and Modeling (pp. 23-40). Springer Netherlands. doi:10.1007/978-94-007-0449-7_2

Collins, A., \& Ferguson, W. (1993). Epistemic forms and epistemic games: Structures and strategies to guide inquiry. Educational Psychologist, 28(1), 25-42. doi:10.1207/s15326985ep2801_3

Collins, A., White, B., \& Fadel, C. (in press). What's worth learning: That school won't teach you.

Craig, S., Gholson, B., \& Driscoll, D. (2002). Animated pedagogical agents in multimedia educational environments: Effects of agent properties, picture features, and redundancy. Journal of Educational Psychology, 94(2), 428-434. doi:10.1037/0022-0663.94.2.428

De Koning, B., Tabbers, H., Rikers, R., \& Paas, F. (2007). Attention cueing as a means to enhance learning from an animation. Applied Cognitive Psychology, 21(6), 731-746. doi:10.1002/acp.1346

Dufour-Janvier, B., Bednarz, N., \& Belanger, M. (1987). Pedagogical considerations concerning the problem of representation. In C. Janvier (Ed.), Problems of representation in the teaching and learning of mathematics. Hillsdale, NJ: LEA.

Duschl, R. A., Schweingruber, H. A., \& Shouse, A. W. (Eds.). (2007). Taking Science to School: Learning and Teaching Science in Grades K-8. National Research Council Board on Science Education, Center for Education, Division of Behavioral and Social Sciences and Education. Washington, DC: The National Academies Press.

Edelson, D. C., Gordin, D. N., \& Pea, R. D. (1999). Addressing the challenges of inquiry-based learning through technology and curriculum design. Journal of the Learning Sciences, 8(3-4), 391-450. doi:10.1080/1050840 6.1999 .9672075

Enyedy, N. (2005). Inventing mapping: Creating cultural forms to solve collective problems. Cognition and Instruction, 23(4), 427-466. doi:10.1207/s1532690xci2304_1

Furberg, A., Kluge, A., \& Ludvigsen, S. (2013). Student sensemaking with science diagrams in a computerbased setting. International Journal of Computer-Supported Collaborative Learning, 8(1), 41-64. doi:10.1007/ s11412-013-9165-4

Gee, J. P. (1990). Social linguistics and literacies: Ideology in discourses. London: Falmer Press.

Gee, J. P. (2007). Good video games and good learning: Collected essays on video games, learning and literacy (New literacies and digital epistemologies). Peter Lang Pub Inc. doi:10.3726/978-1-4539-1162-4

Giere, R. N. (1988). Explaining science: A cognitive approach. Chicago: University of Chicago Press. doi:10.7208/ chicago/9780226292038.001.0001

Ginns, P. (2005). Meta-analysis of the modality effect. Learning and Instruction, 15(4), 313-331. doi:10.1016/j. learninstruc.2005.07.001 
Gravemeijer, K., Cobb, P., Bowers, J., \& Whitenack, J. (2000). Symbolizing, modeling, and instructional design. In P. Cobb, E. Yackel, \& K. McClain (Eds.), Symbolizing and communicating in mathematics classrooms: Perspectives on discourse, tools, and instructional design. Mahwah, NJ: Lawrence Erlbaum Associates.

Habgood, M. P. J., \& Ainsworth, S. E. (2011). Motivating children to learn effectively: Exploring the value of intrinsic integration in educational games. Journal of the Learning Sciences, 20(2), 169-206. doi:10.1080/10 508406.2010.508029

Hall, R., \& Stevens, R. (1995). Making space: A comparison of mathematical work in school and professional design practices. In S. L. Star (Ed.), The cultures of computing (pp. 118-145). London, UK: Basil Blackwell.

Han, I., Black, J. B., \& Hallman, G. Jr. (2011). Incorporating haptic feedback in simulation for learning physics. Computer Education, 57(4), 2281-2290. doi:10.1016/j.compedu.2011.06.012

Hasler, B., Kersten, B., \& Sweller, J. (2007). Learner control, cognitive load and instructional animation. Applied Cognitive Psychology, 21(6), 713-729. doi:10.1002/acp.1345

Hegarty, M. (1992). Mental animation: Inferring motion from static diagrams of mechanical systems. Journal of Experimental Psychology. Learning, Memory, and Cognition, 18(5), 1084-1102. doi:10.1037/02787393.18.5.1084 PMID:1402712

Hegarty, M. (2004). Dynamic visualizations and learning: Getting to the difficult questions. Learning \& Instruction, 14(3), 343-352.

Hegarty, M., \& Just, M. A. (1993). Constructing mental models of machines from text and diagrams. Journal of Memory and Language, 32(6), 717-742. doi:10.1006/jmla.1993.1036

Hegarty, M., Kriz, S., \& Cate, C. (2003). The roles of mental animations and external animations in understanding mechanical systems. Cognition and Instruction, 21(4), 209-249. doi:10.1207/s1532690xci2104_1

Hegedus, S., \& Roschelle, J. (Eds.). (2013). The SimCalc vision and contributions: Democratizing access to important mathematics. New York, NY: Springer. doi:10.1007/978-94-007-5696-0

Hsu, C.-Y., Tsai, C.-C., \& Wang, H. Y. (2012). Facilitating third graders' acquisition of scientific concepts through digital game-based learning: The effects of self-explanation principles. The Asia-Pacific Education Researcher, 21(1), 71-82.

Huang, S. C., Vea, T., \& Black, J. (2011, October). Learning classic mechanics with embodied cognition. In Proceedings of the World Conference on E-Learning in Corporate, Government, Healthcare, and Higher Education (Vol. 2011, No. 1, pp. 209-215).

Huang, S. C. D. (2013). Grounded learning experience: Helping students learn physics through visuo-haptic priming and instruction [Doctoral dissertation]. Columbia University.

Jang, S., Black, J. B., \& Jyung, R. W. Embodied Cognition and Virtual Reality in Learning to Visualize Anatomy. In Proceedings of the 32nd Annual Conference of the Cognitive Science Society, Portland, OR, August (pp. 12-14).

Jeung, H., Chandler, P., \& Sweller, J. (1997). The role of visual indicators in dual sensory mode instruction. Educational Psychology, 17(3), 329-345. doi:10.1080/0144341970170307

Jones, S. (1998). Diagram representation: a comparison of animated and static formats. Unpublished $\mathrm{PhD}$ thesis, School of Computing and Cognitive Sciences, University of Sussex, UK.

Kalyuga, S., Chandler, P., \& Sweller, J. (1998). Levels of expertise and instructional design. Human Factors, 40(1), 1-17. doi:10.1518/001872098779480587

Kalyuga, S., Chandler, P., \& Sweller, J. (1999). Managing split-attention and redundancy in multimedia instruction. Applied Cognitive Psychology, 13(4), 351-371. doi:10.1002/(SICI)1099-0720(199908)13:4<351::AIDACP589>3.0.CO;2-6

Kaput, J. (1994). Democratizing access to calculus: New routes using old roots. In A. Schoenfeld (Ed.), Mathematical thinking and problem solving (pp. 77-156). Hillsdale, NJ: LEA.

Kaput, J. J. (1992). Technology and mathematics education. In D. A. Grouws (Ed.), Handbook of teaching and learning mathematics. New York: Macmillan. 
Kiili, K. (2005). On educational game design: Building blocks of flow experience. Tampere, Finland: Tampere University of Technology Press.

Kiili, K., \& Lainema, T. (2008). Foundation for measuring engagement in education games. Journal of Interactive Learning Research, 19(3), 469-488.

Kriz, S., \& Hegarty, M. (2004). Constructing and revising mental models of a mechanical system: The role of domain knowledge in understanding external visualizations. In Proceedings of the 26th Annual Conference of the Cognitive Science Society. Mahwah, NJ: Lawrence Erlbaum Associates.

Larkin, J. H., \& Simon, H. A. (1987). Why a diagram is (sometimes) worth 10000 words. Cognitive Science, 11(1), 65-99. doi:10.1111/j.1551-6708.1987.tb00863.x

Lehrer, R., \& Schauble, L. (2002). Symbolic communication in mathematics and science: Co-constituting inscription and thought. In E. Amsel \& J. Byrnes (Eds.), The development of symbolic communication. Mahwah, NJ: Lawrence Erlbaum Associates.

Lehrer, R., \& Schauble, L. (2006). Cultivating model-based reasoning in science education. In R. K. Sawyer (Ed.), The Cambridge Handbook of the Learning Sciences (pp. 371-388). Cambridge, England: Cambridge University Press.

Lehrer, R., \& Schauble, L. (2009). Images of learning, images of progress. Journal of Research in Science Teaching, 46(6), 731-735. doi:10.1002/tea.20317

Lehrer, R., \& Schauble, L. (2010). What kind of explanation is a model? In M. K. Stein (Ed.), Instructional explanations in the disciplines (pp. 9-22). New York: Springer. doi:10.1007/978-1-4419-0594-9_2

Leinhardt, G., Zaslavsky, O., \& Stein, M. M. (1990). Functions, graphs, and graphing: Tasks, learning and teaching. Review of Educational Research, 60(1), 1-64. doi:10.3102/00346543060001001

Lowe, R. K. (2003). Animation and learning: Selective processing of information in dynamic graphics. Learning and Instruction, 13(2), 157-176. doi:10.1016/S0959-4752(02)00018-X

Lu, C., Black, J., Kang, S., \& Huang, S. (2011). The Effects of LEGO Robotics and Embodiment in Elementary Science Learning. In Proceedings of the 33rd Annual Conference of the Cognitive Science. Cognitive Science Society, Austin, TX.

Lusk, M., \& Atkinson, R. (2007). Animated pedagogical agents: Does their degree of embodiment impact learning from static or animated worked examples? Applied Cognitive Psychology, 21(6), 747-764. doi:10.1002/acp.1347

Madden, S. P., Jones, L. L., \& Rahm, J. (2011). The Role of Multiple Representations in the Understanding of Ideal Gas Problems. Chemistry Education Research and Practice, 12(3), 283-293. doi:10.1039/C1RP90035H

Mautone, P. D., \& Mayer, R. E. (2001). Signaling as a cognitive guide in multimedia learning. Journal of Educational Psychology, 93(2), 377-389. doi:10.1037/0022-0663.93.2.377

Mayer, R., Dow, G., \& Mayer, S. (2003). Multimedia learning in an interactive self explaining environment: What works in the design of agent-based microworlds? Journal of Educational Psychology, 95(4), 806-812. doi:10.1037/0022-0663.95.4.806

Mayer, R. E. (2005c). Principles for managing essential processing in multimedia learning: segmenting, presenting and modality principles. In R. E. Mayer (Ed.), The Cambridge handbook of multimedia learning (pp. 169-182). New York, NY: Cambridge University Press. doi:10.1017/CBO9780511816819.012

Mayer, R. E., \& Chandler, P. (2001). When learning is just a click away: Does simple user interaction foster deeper understanding of multimedia messages? Journal of Educational Psychology, 93(2), 390-397. doi:10.1037/00220663.93.2.390

Mayer, R. E., \& Johnson, C. I. (2010). Adding instructional features that promote learning in a game-like environment. Journal of Educational Computing Research, 42(3), 241-265. doi:10.2190/EC.42.3.a

Mokros, J. R., \& Tinker, R. F. (1987). The impact of microcomputer-based labs on children's ability to interpret graphs. Journal of Research in Science Teaching, 24(4), 369-383. doi:10.1002/tea.3660240408

Moreno, R., \& Mayer, R. (2007). Interactive multimodal learning environments. Educational Psychology Review, 19(3), 309-326. doi:10.1007/s10648-007-9047-2 
Moreno, R., \& Mayer, R. E. (1999). Cognitive principles of multimedia learning: The role of modality and contiguity. Journal of Educational Psychology, 91(2), 358-368. doi:10.1037/0022-0663.91.2.358

Morrison, D., \& Collins, A. (1995). Epistemic fluency and constructivist learning environments. Educational Technology, 35(5), 39-45.

Nersessian, N. J. (2002). The cognitive basis of model-based reasoning in science. In P. Carruthers, S. Stich, \& M. Siegal (Eds.), The cognitive basis of science (pp. 133-155). Cambridge: Cambridge University Press. doi:10.1017/CBO9780511613517.008

Paek, S. (2012). The impact of multimodal virtual manipulatives on young children's mathematics learning [Doctoral dissertation]. Teachers College, Columbia University.

Pickering, A. (1995). The mangle of practice: Time, agency, and science. Chicago: University of Chicago Press. doi:10.7208/chicago/9780226668253.001.0001

Plotzner, R. (1995). The construction and coordination of complementary problem representations in physics. Journal of Artificial Intelligence in Education, 6(2/3), 203-238.

Preece, J., \& Janvier, C. (1992). A study of the interpretation of trends in multiple curve graphs of ecological situations. School Science and Mathematics, 92(6), 299-306. doi:10.1111/j.1949-8594.1992.tb15595.x

Rapp, D. N., \& Sengupta, P. (2012). Models and modeling in science learning Encyclopedia of the Sciences of Learning (pp. 2320-2322). New York: Springer.

Reif, F., \& Scott, L. A. (1999). Teaching scientific thinking skills: Students and computers coaching each other. American Journal of Physics, 67(9), 819-831. doi:10.1119/1.19130

Resnick, L. B., \& Omanson, S. (1987). Learning to understand arithmetic. In R. Glaser (Ed.), Advances in instructional psychology (pp. 41-95). Hillsdale, NJ: LEA.

Rittle-Johnson, B., \& Star, J. R. (2007). Does comparing solution methods facilitate conceptual and procedural knowledge: An experimental study on learning to solve equations. Journal of Educational Psychology, 99(3), 561-574. doi:10.1037/0022-0663.99.3.561

Rittle-Johnson, B., Star, J. R., \& Durkin, K. (2012). Developing procedural flexibility: Are novices prepared to learn from comparing procedures? The British Journal of Educational Psychology, 82(3), 436-455. doi:10.1111/ j.2044-8279.2011.02037.x PMID:22881048

Rittschof, K. A., Stock, W. A., Kulhavy, R. W., Verdi, M. P., \& Johnson, J. T. (1996). Learning from cartograms: The effects of region familiarity. The Journal of Geography, 95(2), 50-58. doi:10.1080/00221349608978925

Roy, M., \& Chi, M. T. H. (2005). The self-explanation principle in multimedia learning. In R. E. Mayer (Ed.), The Cambridge handbook of multimedia learning (pp. 271-286). New York: Cambridge University Press. doi:10.1017/CBO9780511816819.018

Russell, J., Kozma, R., Becker, D., \& Susskind, T. (2000). SMV: Chem; Synchronized Multiple Visualizations in Chemistry. New York: John Wiley.

Scheiter, K., Gerjets, P., Huk, T., Imhof, B., \& Kammerer, Y. (2009). The effects of realism in learning with dynamic visualizations. Learning and Instruction, 19(6), 481-494. doi:10.1016/j.learninstruc.2008.08.001

Schwartz, D. L., Chase, C. C., Oppezzo, M. A., \& Chin, D. B. (2011). Practicing versus inventing with contrasting cases: The effects of telling first on learning and transfer. Journal of Educational Psychology, 103(4), 759-775. doi:10.1037/a0025140

Sengupta, P., \& Clark, D. B. (2016). Playing Modeling Games in the Science Classroom: The Case for Disciplinary Integration. Educational Technology, 56(3), 16-22.

Seufert, T. (2003). Supporting coherence formation in learning from multiple representations. Learning and Instruction, 13(2), 227-237. doi:10.1016/S0959-4752(02)00022-1

Shah, P., \& Shellhammer, D. (1999). The role of domain knowledge and graph reading skills in graph comprehension. In meeting of the Society for Applied Research in Memory and Cognition, Boulder, CO.

Spanjers, I., \& Van Merrienboer, J. (2010). A Theoretical analysis of how segmentation of dynamic visualizations optimizes students' learning. Educational Psychology Review, 22(4), 411-423. doi:10.1007/s10648-010-9135-6 
Squire, K. (2011). Video games and learning: Teaching and participatory culture in the digital age. New York: Teachers College Press.

Squire, K., Barnett, M., Grant, J. M., \& Higginbotham, T. (2004). Electromagnetism supercharged!: Learning physics with digital simulation games. In Proceedings of the 6th International Conference of the Learning Sciences (pp. 513-520).

Stieff, M., Hegarty, M., \& Deslongchamps, G. (2011). Identifying representational competence with multirepresentational displays. Cognition and Instruction, 29(1), 123-145. doi:10.1080/07370008.2010.507318

Stull, A. T., Hegarty, M., Dixon, B., \& Stieff, M. (2012). Representational Translation With Concrete Models in Organic Chemistry. Cognition and Instruction, 30(4), 404-434. doi:10.1080/07370008.2012.719956

Tversky, B., Heiser, J., Mackenzie, R., Lozano, S., \& Morrison, J. (2008). Enriching animations. In Learning with animation: Research implications for design (pp. 304-356).

van der Meij, J., \& De Jong, T. (2003, August). Learning with multiple representations. Supporting students' translation between representations in a simulation-based learning environment. In Proceedings of the EARLI conference 2003, Padoua.

van der Meij, J., \& de Jong, T. (2006). Supporting students' learning with multiple representations in a dynamic simulation-based learning environment. Learning and Instruction, 16(3), 199-212. doi:10.1016/j. learninstruc.2006.03.007

van der Meij, J., \& de Jong, T. (2011). The effects of directive self-explanation prompts to support active processing of multiple representations in a simulation-based learning environment. Journal of Computer Assisted Learning, 27(5), 411-423. doi:10.1111/j.1365-2729.2011.00411.x

VanLehn, K. (2011). The relative effectiveness of human tutoring, intelligent tutoring systems, and other tutoring systems. Educational Psychologist, 46(4), 197-221. doi:10.1080/00461520.2011.611369

Verdi, M. P., Johnson, J. T., Stock, W. A., Kulhavy, R. W., \& Whitman, P. (1997). Organized spatial displays and texts: Effects of presentation order and display type on learning outcomes. Journal of Experimental Education, 65(4), 303-317. doi:10.1080/00220973.1997.10806606

White, B. Y. (1993). ThinkerTools: Causal models, conceptual change, and science education. Cognition and Instruction, 10(1), 1-100. doi:10.1207/s1532690xci1001_1

Zhang, J. J. (1996). A representational analysis of relational information displays. International Journal of Human-Computer Studies, 45(1), 59-74. doi:10.1006/ijhc.1996.0042

Zhang, Z. H., \& Linn, M. C. (2011). Can generating representations enhance learning with dynamic visualizations? Journal of Research in Science Teaching, 48(10), 1177-1198. doi:10.1002/tea.20443

Satyugjit S. Virk holds a PhD in Cognition and Technology from Teachers College, CU. He has created and researched science simulations for neuroscience, earth science and circuits and capacitors for physics. He was the head of Cognition and $R \& D$ at InteractAble, a startup producing a cutting edge visually systematic adaptive gaming platform for children with autism. He was also a post-doctoral fellow at Vanderbilt designing and researching cognition based complex interfaces for teaching physics to kids through games with an emphasis on linking concrete visualizations to abstract ones. Currently, he is a machine learning engineer and UX/Cognition Researcher in the Greater Bay Area.

Douglas B. Clark is a Professor of Design-Based Learning and the Learning Sciences at University of Calgary. He researches students' conceptual change processes and approaches for scaffolding those processes in games and other technology-rich environments. Clark is currently PI of the NSF DRK12 Enhancing Games with Assessment and Metacognitive Emphases (EGAME) grant that focus on scaffolding students' conceptual change processes in digital game based environments as well as developing approaches for analyzing game-play data in real-time for formative evaluation and adaption of student's experiences in those environments. Clark is also Co-PI on Extending CTSiM: An Adaptive Computational Thinking Environment for Learning Science through Modeling and Simulation in Middle School Classrooms. Clark was PI of the Department of Education IES Explanation and Prediction Increasing Gains and Metacognition (EPIGAME) grant and the exploratory NSFDRK12 grant Scaffolding Understanding by Redesigning Games for Education (SURGE), CoPI on the NSF Cyberlearning grant Fostering Computational Thinking in Middle Schools through Scientific Modeling and Simulation (CTSiM), and was also on the leadership team for the NSF CLT grant Technology Enhanced Learning in Science (TELS). 